\title{
Rechargeable Aqueous Electrolyte Batteries: from Univalent to Multivalent Cations Chemistry
}

\author{
Rezan Demir-Cakan ${ }^{\mathrm{a}, \mathrm{b}}$, M. Rosa Palacin ${ }^{\mathrm{c}, \mathrm{e}}$ and Laurence Croguennec $\mathrm{d}^{\mathrm{de}, \mathrm{f}, *}$ \\ *e-mail: laurence.croguennec@icmcb.cnrs.fr
}

\footnotetext{
${ }^{a}$ Department of Chemical Engineering, Gebze Technical University, 41400, Gebze, Kocaeli, Turkey

${ }^{\mathrm{b}}$ Institute of Nanotechnology, Gebze Technical University, 41400, Gebze, Kocaeli, Turkey

${ }^{\mathrm{c}}$ Institut de Ciència de Materials de Barcelona, (ICMAB-CSIC), Campus UAB, 08193 Bellaterra, Catalonia, Spain

${ }^{\mathrm{d}}$ CNRS, Univ. Bordeaux, Bordeaux INP, ICMCB UMR 5026, F-33600 Pessac, France.

e ALISTORE-ERI European Research Institute, FR CNRS 3104, F-80039 Amiens Cedex 1, France.

${ }^{\mathrm{f}}$ RS2E, Réseau Français sur le Stockage Electrochimique de l'Energie, FR CNRS 3459, F-80039 Amiens Cedex 1, France.
}

\begin{abstract}
Water based electrolytes enable very high ionic conductivity, and are particularly attractive for high power density batteries. The main advantages of water-based electrolytes are their lower cost and nonflammability, while their principal disadvantage is the limited thermodynamic electrochemical window of water. Yet, the latter is currently being challenged, through the use of highly concentrated electrolytes, ("water in salt concept").

Strong research focus is currently placed on rechargeable $\mathrm{M}$-ion batteries $(\mathrm{M}=\mathrm{Li}, \mathrm{Na})$ mimicking the organic Li-ion or Na-ion, which will despite falling shorter in energy density exhibit cost advantages. Moreover, they should be expected to delivering very attractive power densities. The main challenge at this stage is the development of new negative electrodes able to operate at lower potentials.

A more challenging topic is divalent ion concepts $(\mathrm{M}=\mathrm{Zn})$ using a $\mathrm{Zn}$ metal anode which could, in principle, deliver higher energy density, but for which issues still remain related to (i) develop appropriate positive electrode materials for reversible $\mathrm{Zn}$ ion insertion and (ii) side reactions involving mostly $\mathrm{H}^{+}$or $\mathrm{OH}^{-}$species, which are not yet mastered.
\end{abstract}

\section{Key learning points}

(1) Featuring the most recent advances in aqueous electrolyte metal-ion battery systems and probing their challenging issues.

(2) Understanding the cell chemistries and underlining their different behaviours in aqueous and non-aqueous media.

(3) Defining cutting-edge characterization tools to investigate the insertion/deinsertion phenomena in waterbased electrolytes: reaction mechanisms and side reactions.

(4) Presenting rigorous information beneficial for the readers both from academia and industry. 


\section{Introduction}

Batteries are electrochemical energy storage devices which are used in many applications ranging from mobile to stationary applications and requiring very different energy densities. Batteries are made of two electrodes involving different redox couples that are separated by an ion conducting medium, the electrolyte, typically a liquid with a certain concentration of dissolved salt. Independent of being single-use or rechargeable batteries, upon discharge, electrons transfer from one electrode to the other through the external circuit and charges are compensated by ions' migration across the electrolyte. If the reaction is reversible, the process can be reversed applying an external current and thus batteries can be recharged. The voltage of the cell depends on the difference in potential between the redox couples involved at the electrodes, while the electrochemical capacity of each given electrode material depends on the number of electrons exchanged per formula weight. The balance between the two electrodes and the product of both magnitudes, voltage and capacity, determines the maximum energy density attainable. The energy stored per mass unit differs from $20 \mathrm{Wh} / \mathrm{kg}$ to $250 \mathrm{Wh} / \mathrm{kg}$ in commercial cells and depends on both the cell design, which includes the total mass of "inactive weight" such as packaging foils, pole tabs, separators or electrolyte, and the "active weight" as electrode materials. Energy density, Wh $(1 \mathrm{Wh}=3600 \mathrm{~J})$, is calculated by the multiplication of the cell potential difference between the negative and the positive electrodes (in Volts) and the cell capacity typically given in Ah.

There are only a few battery technologies commercially relevant. From those dominating the market in terms of size and value ( $\mathrm{Li}$-ion, $\mathrm{Pb} / \mathrm{acid}$ and alkaline $\mathrm{Ni}$ based either $\mathrm{Ni} / \mathrm{Cd}$ or $\mathrm{Ni} / \mathrm{MH}$, see Fig. 1 for the reactions involved, their cell voltage and specific energy), all except $\mathrm{Li}$-ion batteries are using aqueous electrolytes. This is related to their historical background, as all of them were developed at the end of the $19^{\text {th }}$ century. Indeed, water was the most readily available solvent and almost the only one used before the widespread use of non-aqueous solvents began in the 1950s, in various fields of pure and applied chemistry. The use of organic solvent based electrolytes with a wider stability window enabled commercialization of the Li-ion technology with large cell potential (3-4 V) and thus higher energy density, despite some drawbacks associated to the need of building the cells in a moisture free environment. Yet, the interest in aqueous battery technologies has recently re-emerged, the main advantages of water-based electrolytes being their lower cost and non-flammability. Furthermore, due to very high ionic conductivities the waterbased electrolytes are particularly attractive for high power density batteries.

Besides attempting to incrementally improve classical technologies (such as $\mathrm{Pb} /$ acid or $\mathrm{Ni}-\mathrm{MH}$ ), current research in the field of rechargeable aqueous electrolyte batteries focuses on two different approaches:

i) metal anode based, coupled to air cathodes for high energy density and

ii) metal-ion ( $\mathrm{M}=\mathrm{Li}, \mathrm{Na}, \mathrm{Zn}$ etc.) batteries mimicking their organic electrolyte counterparts.

The former has the intrinsic unsolved issues related to air electrodes, coupled to concerns related to dendritic growth, for instance, $\mathrm{Zn}$ metal anodes suffer from poor rechargeability, with performance limiting phenomena ascribed to mainly dendrite growth in alkaline environment. The most attractive figures would come for Li/air, but in this case protection of the $\mathrm{Li}$ anode to avoid $\mathrm{H}_{2}$ formation is mandatory, which adds cost and complexity (and safety risks) to the system. In contrast, the batteries based on metal-ion offer very interesting prospects and could challenge the hybrid supercapacitors [1, 
2] delivering very attractive power densities combined with intermediate energy densities that could fulfil the requirements for grid applications.

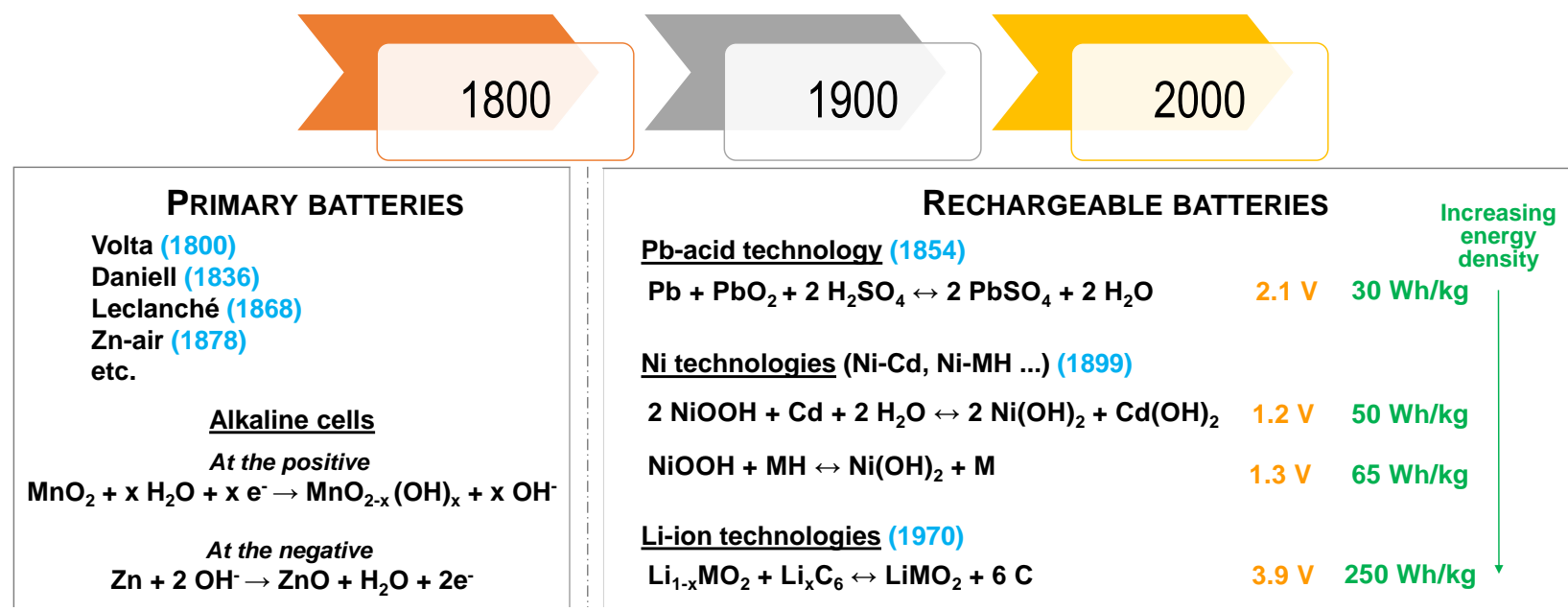

Figure 1: Commercially relevant aqueous battery technologies, compared to the Li-ion batteries. The date of the first published report on the main technologies are given between brackets in blue.

This review deals with the state-of-the-art research in metal-ion rechargeable battery technologies using aqueous electrolytes. Even if some mentions will be made in passing, no attempt will be done to cover primary chemistries or conventional nickel or lead based rechargeable technologies. Metal/air and redox flow concepts will not be discussed either. Different from the already existing reviews on aqueous electrolyte batteries [3-11], hereby, we keep the scope to univalent and multivalent cation chemistries namely $\mathrm{Li} / \mathrm{Na}$-ion and $\mathrm{Zn}$-ion technologies providing in-depth description of their reaction mechanisms by probing different characterization tools as well as covering common technological challenging issues and perspectives to solve them.

In contrast to battery concepts in which the charge carrier ions are $\mathrm{H}^{+}, \mathrm{Li}^{+}$or $\mathrm{Na}^{+}$, batteries based on multivalent metal-ions (i.e. $\mathrm{Mg}^{2+}, \mathrm{Ca}^{2+}, \mathrm{Zn}^{2+}, \mathrm{Ni}^{2+}, \mathrm{Al}^{3+}$, etc.) involve more than one electron transfer per ion. Table 1 shows the standard electrode potentials, ionic radii and theoretical capacities derived from metallic cation electrodeposition. From these values it can be deduced that only Ni (-0.257 V vs SHE) and Zn (-0.76 V vs SHE) metals can be used as metal electrodes in aqueous medium, as they fall within the water stability window. The voltage range associated to the decomposition of water is not an exact value as known from the Pourbaix diagram, instead, to be directly linked to the $\mathrm{pH}$ of the electrolyte $E_{\mathrm{H}^{+} / \mathrm{H}_{2}}=E_{\mathrm{H}^{+} / \mathrm{H}_{2}}^{0}-0.059 \mathrm{pH}$ (see Figure 2a). The standard reduction potential for the other metals is lower and falls outside the water thermodynamic stability window. Thus, water reduction to $\mathrm{H}_{2}$ occurs before metal ions are plated (electrodeposited) on the negative electrode. $\mathrm{Zn}$ is the most electropositive metal that can be electrodeposited in water and it is a very attractive negative electrode, as it can exhibit high capacity $\left(820 \mathrm{mAh} \mathrm{g}^{-1}\right)$. These factors are most likely at the origin of recent renewed interest to develop $\mathrm{Zn}$ based rechargeable batteries. 
Table 1: Standard electrode potentials, ionic radii and theoretical capacities of different metal ions

\begin{tabular}{ccccc}
\hline Ions & $\begin{array}{c}\text { Voltage } \\
(\text { vs SHE) })\end{array}$ & $\begin{array}{c}\text { Ionic radif } \\
(\mathbf{A})\end{array}$ & $\begin{array}{c}\text { Theoretical gravimetric capacity } \\
(\mathrm{mAh} / \mathrm{g})\end{array}$ & $\begin{array}{c}\text { Theoretical volumetric capacity } \\
\left(\mathrm{mAh} / \mathrm{cm}^{3}\right)\end{array}$ \\
\hline $\mathrm{Li}^{+}$ & -3.05 & 0.76 & 3829 & 2044 \\
$\mathrm{Na}^{+}$ & -2.71 & 1.02 & 1165 & 1128 \\
$\mathrm{Ca}^{2+}$ & -2.87 & 0.99 & 1337 & 2073 \\
$\mathrm{Mg}^{2+}$ & -2.36 & 0.66 & 2234 & 3882 \\
$\mathrm{Al}^{3+}$ & -1.66 & 0.53 & 2980 & 8046 \\
$\mathrm{Zn}^{2+}$ & -0.76 & 0.74 & 820 & 5854 \\
$\mathrm{Ni}^{2+}$ & -0.257 & 0.72 & 913 & 8133 \\
\hline
\end{tabular}

\section{Water as Electrolyte}

Water is considered as universal solvent and can dissolve large concentrations of diverse ionic compounds. Its high dielectric constant and low viscosity $\left(80\right.$ and $1 \mathrm{cP}$ respectively at $20^{\circ} \mathrm{C}$ ) enable a very high ionic conductivity for aqueous electrolytes (i.e. $\sim 1 \mathrm{~S} / \mathrm{cm}$ in $\mathrm{H}_{2} \mathrm{SO}_{4}$ containing aqueous electrolyte), which is two orders of magnitude higher than that achieved with the organic electrolytes used in Li-ion batteries $\left(\sim 10^{-2} \mathrm{~S} / \mathrm{cm}\right.$ for $\mathrm{LiPF}_{6}$ dissolved in conventional carbonate based solvents) and hence aqueous technologies are appealing for high power density. Water solvates most of the salts straightforwardly due to the coexistence of Lewis basicity at the oxygen site and acidity at the hydrogen site. Then, desolvation enthalpy $\mathrm{of}^{\mathrm{Li}^{+}}$ions is much lower in water when compared to organic electrolytes used in conventional $\mathrm{Li}$-ion batteries $(-34 \mathrm{kcal} / \mathrm{mol}$ in water $v s-51 \mathrm{kcal} / \mathrm{mol}$ in propylene carbonate) [12]. In contrast, aqueous electrolytes are more corrosive than organic solutions and have a narrower thermal application range as their low temperature performance is limited by the freezing point.

The role of the electrolyte in batteries is less eye-catching but equally important as that of the electrode materials, as the energy separation between the lowest unoccupied molecular orbital (LUMO) and the highest occupied molecular orbital (HOMO) of its components determines the thermodynamic electrochemical stability window and hence the maximum potential attainable at cell level [13]. This window should be as wide as possible to enable compatibility with the strongly reducing/oxidizing electrode active materials and hence increase the energy density of the system. The theoretical thermodynamic electrochemical window of water is $1.23 \mathrm{~V}$. This stability window is dependent on $\mathrm{pH}$ value $(0.059 \mathrm{~V}$ per $\mathrm{pH}$ unit), as can be seen from the Pourbaix diagram given in Fig. 2. Despite this very limited thermodynamic voltage stability, in some practical cases the useful range can be extended due to degradation reactions being kinetically limited. For instance, it can attain $2 \mathrm{~V}$ for the $\mathrm{Pb} / \mathrm{acid}$ technology due to the high overvoltage for the $\mathrm{H}_{2}$ evolution on $\mathrm{Pb}$ electrodes [14]. Indeed, water decomposition reactions (via electrolysis) involve an over potential at the surface of the electrode materials, water molecules' adsorption/desorption at the surface of the electrodes induces local $\mathrm{pH}$ variations which shift the decomposition reactions at higher and/or at lower voltages. The water stability window can also be tuned/widened by the choice of the electrolyte salt and of its concentration (e.g. from more acidic $\mathrm{LiNO}_{3}$ and $\mathrm{Li}_{2} \mathrm{SO}_{4}$ to more basic $\mathrm{LiOH}$ ). 

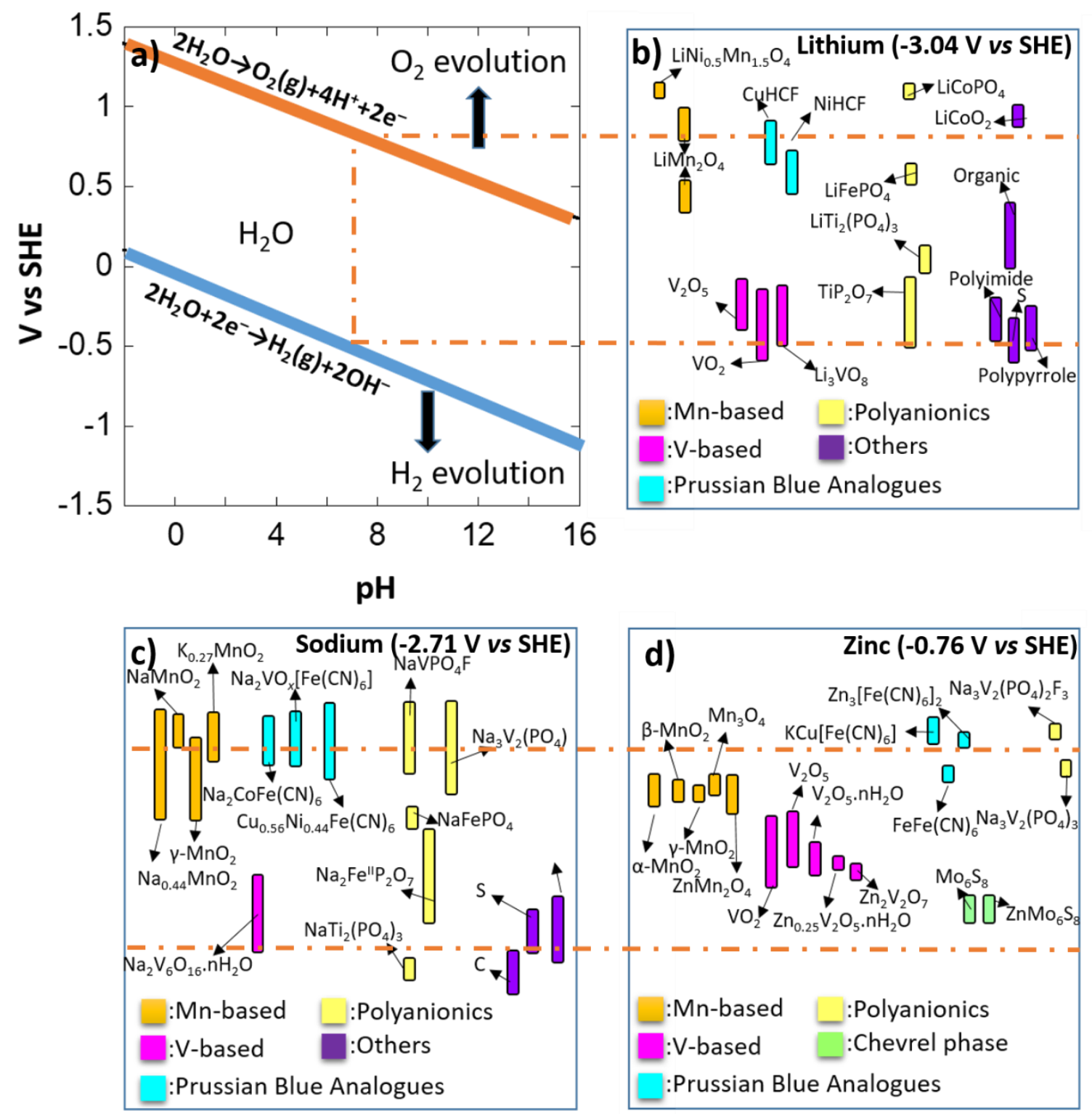

Figure 2: (a) Potential vs $\mathrm{pH}$ stability diagram of water at $1 \mathrm{~atm}$ and $25^{\circ} \mathrm{C}$. Below the equilibrium reaction shown as a continuous blue line decomposition of $\mathrm{H}_{2} \mathrm{O}$ into $\mathrm{H}_{2}$ is favoured, while above the continuous orange line oxidation to produce $\mathrm{O}_{2}$ takes place. Main insertion materials studied as positive and negative electrodes in aqueous rechargeable lithium-ion, sodium-ion and zinc-ion batteries are given in (b), (c) and (d) respectively.

In the case of organic solvent electrolytes, such as those used in the Li-ion battery technology, the thermodynamic stability window is broader than $4 \mathrm{~V}[15,16]$. The degradation of the organic solvents results in the formation of insoluble products adhering to the electrode surface and forming a protective solid passivation layer. This layer is commonly known as solid electrolyte interphase (SEI) since it is ionically conducting and electronically insulating and its presence enables cell operation beyond the thermodynamic stability window of the organic solvent electrolyte. Thus, besides determining the practically accessible energy density, the electrolyte does also play a crucial role in the performance of the battery in terms of life 
duration, as the stability of such passivation layers is crucial to avoid degradation. In aqueous batteries, since water decomposition products are either volatile gases $\left(\mathrm{H}_{2}\right.$ or $\left.\mathrm{O}_{2}\right)$ or reactive ions $\left(\mathrm{H}^{+}\right.$or $\left.\mathrm{OH}^{-}\right)$leading to the formation of water soluble products, such solid passivation layers do not form and hence uncontrolled oxygen/hydrogen evolution at the electrode surfaces takes place outside the stability window. Yet, there have been recent attempts to design aqueous highly concentrated electrolytes to prevent the presence of free water molecules in the electrolyte in which an SEI can be formed. This strategy will be discussed in details in section 6.1.

For an in-depth understanding of the reaction mechanisms involved in different parts of the battery (electrodes, solid-liquid interface between the electrodes and the electrolyte, current collectors, electrolyte, etc.), the involvement of a large panel of complementary characterization tools is needed, from the most widely spread in our laboratories to the most advanced ones [17]. Moreover, different length scales need to be probed from $\AA$ A to $\mathrm{nm}$ for surfaces/interfaces to tenths of $\mathrm{nm}-\mu \mathrm{m}$ for electrode materials, to reach mm for full electrodes and full device [18], and due attention has to be paid to the sensitivity of the technique (surface vs. bulk) and also spatial and time resolution, which may enable mapping of dynamic processes. Different from the engrained energy storage mechanisms (i.e. insertion, conversion or alloying) in non-aqueous electrolyte batteries, additional side reactions might take places in water, which are deleterious to battery operation and may not be easy to detect. Indeed, as can be deduced from the Pourbaix diagram in Fig. 2a, shifting the potential of the positive electrode to higher voltage by decreasing the $\mathrm{pH}$ value of the electrolyte or to lower voltage at the negative electrode by increasing the $\mathrm{pH}$ value may result in generation of hydrogen or oxygen respectively at the opposite electrode. Other possible side reactions include: i) ion exchange between metal ions present in the solid and $\mathrm{H}^{+}$present in the electrolyte, ii) partial dissolution of the active material within the acidic electrolyte, or else iii) $\mathrm{H}^{+}$and/or $\mathrm{H}_{2} \mathrm{O}$ co-insertion together with the charge carrier ion (e.g. $\mathrm{Na}^{+}$) during the electrochemical process etc. The stability of the electrode materials varies with the $\mathrm{pH}$ value, it can thus be challenging to find a couple of positive and negative electrode materials, both stable at the same $\mathrm{pH}$ value to get a stable aqueous system. The presence of protons or water molecules within the structure can be detected combining Fourier transformed infra-red (FTIR) and solid state magic angle spinning nuclear magnetic resonance (MAS NMR) spectroscopies. Depending on the vibration frequencies observed in the FTIR absorption spectrum, the nature of the chemical bonds (atoms involved and their close environment) can be identified. MAS NMR gives additional information on the nature of the chemical bonds and on their electronic environment, as the shift of the NMR signal is characteristic of the spin transfer from the neighbouring paramagnetic transition metal ions towards the probed nucleus, which can be for instance ${ }^{1} \mathrm{H}$. Furthermore, a marked improvement in understanding the charge storage mechanisms has been obtained thanks to recent progress with electrogravimetric methods (electrochemical quartz crystal microbalance (EQCM) [19, 20].

Note that good performance at high rates demonstrates the power performance of the system but does not allow easy detection of side reactions (such as electrolyte decomposition) that depend on the residence time at extreme potentials and hence can more easily be observed at lower rates. Thus, testing in different conditions would be required to assess service life for the different concepts proposed. Since one of the suggested applications is ensuring power supply to data centers, research on the evolution of performance upon storing in different conditions is also mandatory. 


\section{Batteries Based on Univalent Ions}

Aqueous rechargeable univalent alkaline batteries (based on transport of $\mathrm{Li}^{+}$and $\mathrm{Na}^{+}$) have been recently revisited as very appealing alternatives to $\mathrm{Li}$-ion batteries for applications requiring safe and low cost energy storage. The large panel of inorganic materials studied as positive and negative electrode materials for organic Li-ion batteries, and more recently for $\mathrm{Na}$-ion batteries constitutes a rich database of materials to be considered "as a starting point" for aqueous alkali-ion batteries. (see Fig. 2a-c).

\subsection{Aqueous Rechargeable Li-ion Batteries (ARLBs)}

The first aqueous Li-ion battery was developed in 1994 [21], just three years after commercialization of organic electrolyte $\mathrm{Li}$-ion batteries $(\mathrm{LiB})$, using $\mathrm{LiMn}_{2} \mathrm{O}_{4}$ spinel $\left(4.1 \mathrm{~V} \mathrm{vs} \mathrm{Li}^{+} / \mathrm{Li}\right)$ at the positive electrode, $\mathrm{VO}_{2}\left(2.6 \mathrm{~V} \mathrm{vs} \mathrm{Li}^{+} / \mathrm{Li}\right)$ at the negative electrode, and $5 \mathrm{M} \mathrm{LiNO}_{3}+0.001 \mathrm{M} \mathrm{LiOH}$ in water as electrolyte. The addition of $\mathrm{LiOH}$ into the aqueous electrolyte induced an increase of the $\mathrm{pH}$ value to $\sim 5$ and allowed a slight shift of the potential and thus an increased stability of $\mathrm{VO}_{2}(\mathrm{~B})$ versus hydrogen evolution (Fig. 2b). It delivered an average voltage of $1.5 \mathrm{~V}$, and was already shown at that time to be competitive with $\mathrm{Pb}$-acid batteries. Nevertheless, the capacity retention was poor, lower than $50 \%$ after 100 cycles, especially at low rates, which was attributed to water oxidation and side reactions taking place concomitant to reduction/oxidation of $\mathrm{LiMn}_{2} \mathrm{O}_{4}$. [21]. The topic fell into oblivion as a result of progresses in the performance of organic electrolyte LIBs until a renewed interest for this eco-friendly electrochemical storage system appeared in the last few years [22] [23]. A few examples of the main ARLBs reported including materials and performance are given in Table 2 with the structures of the corresponding electrode materials being depicted in Fig. 3.

Table 2: The main examples of the full-cell aqueous Lithium-ion batteries, adapted from [5]

\begin{tabular}{|c|c|c|c|c|c|c|}
\hline Cathode & Anode & Electrolyte & $\begin{array}{c}\text { Current rate } \\
\text { (C rate) }\end{array}$ & Average voltage (V) & $\begin{array}{l}\text { Capacity } \\
\left(\mathrm{mAh} \cdot \mathrm{g}^{-1}\right)\end{array}$ & $\begin{array}{l}\text { Retention (\%) } \\
\text { (no. of cycles) }\end{array}$ \\
\hline $\mathrm{LiMn}_{2} \mathrm{O}_{4}$ & Activated carbon & $1 \mathrm{M} \mathrm{Li}_{2} \mathrm{SO}_{4}$ & $0.2 \mathrm{~A} . \mathrm{g}^{-1}$ & 1.25 & $26^{\mathrm{b}}$ & $98(20000)$ \\
\hline $\mathrm{LiMn}_{2} \mathrm{O}_{4}{ }^{\mathrm{a}}$ & Activated carbon & $0.5 \mathrm{M} \mathrm{Li}_{2} \mathrm{SO}_{4}$ & 1.0 A.g $\mathrm{g}^{-1}$ & 0.9 (vs NHE) & 110 & $93(10000)$ \\
\hline $\mathrm{g}-\mathrm{MnO}_{2}^{\mathrm{a}}$ & Activated carbon & $1 \mathrm{M} \mathrm{LiOH}$ & $0.1{\mathrm{~A} . \mathrm{g}^{-1}}^{-1}$ & 1.0 & 34.7 & $83(1500)$ \\
\hline $\mathrm{LiCoO}_{2}{ }^{\mathrm{a}}$ & Ni grid & $0.5 \mathrm{M} \mathrm{Li}_{2} \mathrm{SO}_{4}$ & $1.0 \mathrm{~A} \cdot \mathrm{g}^{-1}$ & 0.9 (vs SHE) & 130 & $96(40)$ \\
\hline $\mathrm{LiNi}_{1 / 3} \mathrm{Mn}_{1 / 3} \mathrm{Co}_{1 / 3} \mathrm{O}_{2} \mathrm{a}^{2}$ & Activated carbon & $0.5 \mathrm{M} \mathrm{Li}_{2} \mathrm{SO}_{4}$ & $12.8 \mathrm{~A} \cdot \mathrm{g}^{-1}$ & 0.6 (vs SCE) & 90 & $90(50)$ \\
\hline $\mathrm{Na}_{1.16} \mathrm{~V}_{3} \mathrm{O}_{8} \mathrm{a}^{2}$ & $\mathrm{Na}_{1.16} \mathrm{~V}_{3} \mathrm{O}_{8}$ & $4 \mathrm{M} \mathrm{LiCl}$ & $5.0 \mathrm{~A} \cdot \mathrm{g}^{-1}$ & 0.7 (vs SCE) & 150 & $80(100)$ \\
\hline $\mathrm{LiMnPO}_{4}{ }^{\mathrm{a}}$ & $\mathrm{LiTi}_{2}\left(\mathrm{PO}_{4}\right)_{3}$ & $5 \mathrm{M} \mathrm{LiNO}_{3}$ & $\mathrm{C} / 3$ & 0.7 (vs SCE) & 84 & $95(50)$ \\
\hline $\mathrm{LiMn}_{2} \mathrm{O}_{4}^{4}$ & $\mathrm{TiP}_{2} \mathrm{O}_{7}$ & $5 \mathrm{M} \mathrm{LiNO}_{3}$ & $\mathrm{C} / 10$ & 1.35 & $43^{b}$ & $35(25)$ \\
\hline $\mathrm{LiMn}_{2} \mathrm{O}_{4}$ & $\mathrm{LiTi}_{2}\left(\mathrm{PO}_{4}\right)_{3}$ & $1 \mathrm{M} \mathrm{Li}_{2} \mathrm{SO}_{4}$ & $10 \mathrm{~mA} \cdot \mathrm{cm}^{-2}$ & 1.5 & $40^{b}$ & $80(200)$ \\
\hline $\mathrm{LiMn}_{2} \mathrm{O}_{4}$ & $\mathrm{Li}_{\mathrm{x}} \mathrm{V}_{2} \mathrm{O}_{5}$ & $5 \mathrm{M} \mathrm{LiNO}_{3}$ & $\mathrm{C} / 5$ & 1.0 & $45^{b}$ & $78(60)$ \\
\hline $\mathrm{LiFePO}_{4}{ }^{\mathrm{a}}$ & $\mathrm{LiV}_{3} \mathrm{O}_{8}$ & $9 \mathrm{M} \mathrm{LiNO}_{3}$ & $10 \mathrm{C}$ & 0.3 (vs SCE) & 90 & $99(100)$ \\
\hline $\mathrm{LiCoO}_{2}{ }^{\mathrm{a}}$ & $\mathrm{LiV}_{3} \mathrm{O}_{8}$ & satd $\mathrm{LiNO}_{3}$ & $1 \mathrm{C}$ & 1.2 & 35 & $53(100)$ \\
\hline $\mathrm{LiMn}_{2} \mathrm{O}_{4}^{a}$ & $\mathrm{TiO}_{2}$ & $3.5 \mathrm{M} \mathrm{LiCl} / 0.25 \mathrm{M} \mathrm{Li}_{2} \mathrm{SO}_{4}$ & $10 \mathrm{C}$ & 1.9 & 130 & $90(100)$ \\
\hline $\mathrm{LiMn}_{2} \mathrm{O}_{4}$ & $\mathrm{VO}_{2}{ }^{\mathrm{a}}$ & $5 \mathrm{M} \mathrm{LiNO}_{3} / 0.001 \mathrm{M} \mathrm{LiOH}$ & $0.01 \mathrm{~A} . \mathrm{g}^{-1}$ & 1.1 & 63 & $72(50)$ \\
\hline $\mathrm{LiMn}_{2} \mathrm{O}_{4}$ & $\mathrm{Na}_{2} \mathrm{~V}_{6} \mathrm{O}_{16} \cdot 0.14 \mathrm{H}_{2} \mathrm{O}^{\mathrm{a}}$ & satd $\mathrm{Li}_{2} \mathrm{SO}_{4}$ & $0.3 \mathrm{~A} . \mathrm{g}^{-1}$ & 0.6 & 80 & $75(200)$ \\
\hline $\mathrm{LiCOO}_{2}$ & polyimide & $5 \mathrm{M} \mathrm{LiNO}_{3}$ & $0.5 \mathrm{~A}^{-\mathrm{g}^{-1}}$ & 1.2 & $70^{b}$ & $79(200)$ \\
\hline
\end{tabular}

a Specific capacities are calculated with the weight of this electrode.

${ }^{\mathrm{b}}$ Capacity based on total electrodes including both the cathode and anode. 


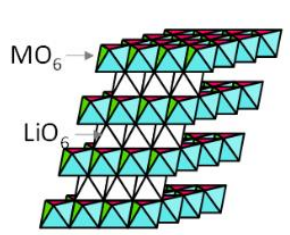

Layered $\mathrm{AMO}_{2}$

$\mathrm{LiCOO}_{2}$

$\mathrm{LiNi}_{1 \beta} \mathrm{Mn}_{1 / 3} \mathrm{Co}_{1 / 3} \mathrm{O}_{2}$

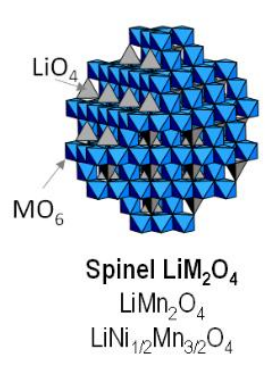

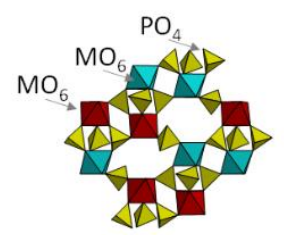

Nasicon $\mathrm{A}_{\mathrm{x}} \mathrm{M}_{2}\left(\mathrm{PO}_{4}\right)_{3}$ $\mathrm{LiTi}_{2}\left(\mathrm{PO}_{4}\right)_{3}$ $\mathrm{NaTi}_{2}\left(\mathrm{PO}_{4}\right)_{3}$

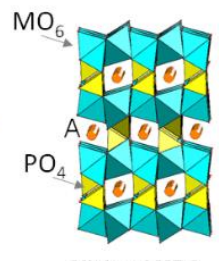

Olivine $\mathrm{AMPO}_{4}$ $\mathrm{LiFePO}_{4}$ $\mathrm{NaFePO}_{4}$

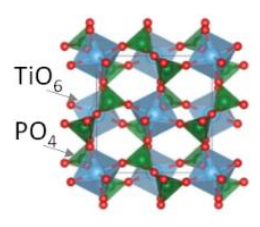

$\mathrm{TiP}_{2} \mathrm{O}_{7}$

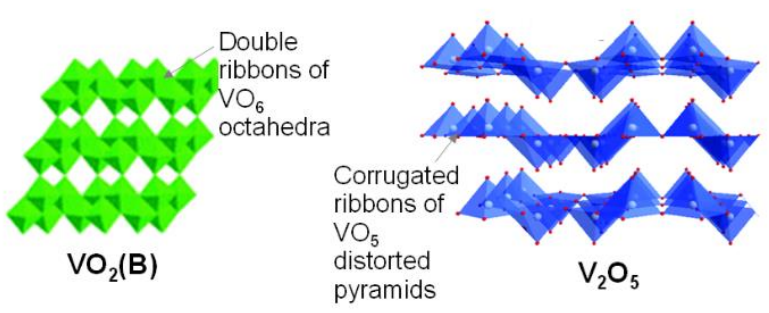

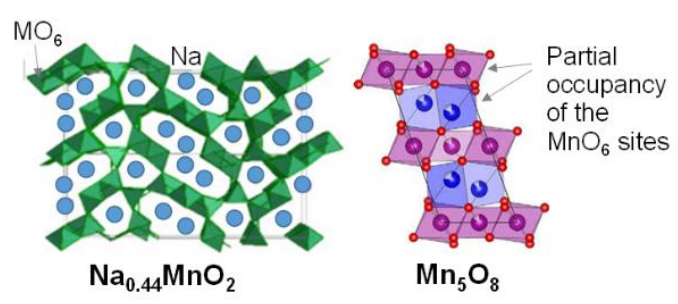
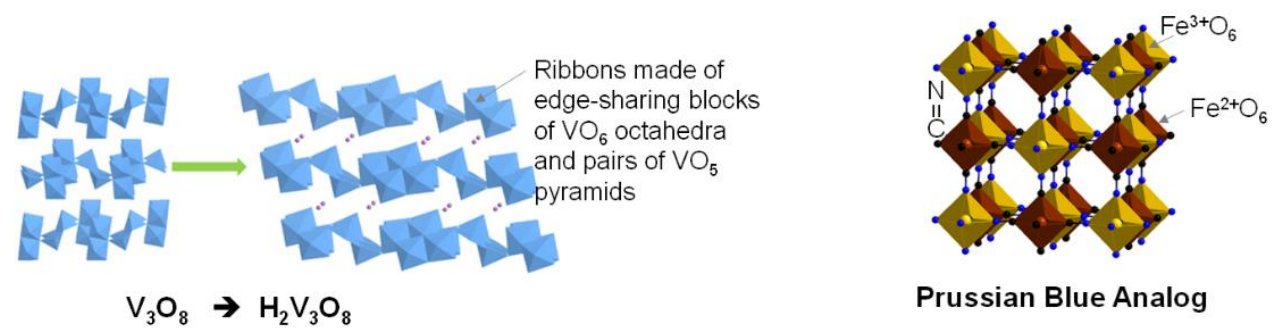

Prussian Blue Analog

Figure 3: Crystal structures of the main inorganic insertion materials used as positive and negative electrodes in aqueous rechargeable alkaline ion batteries.

\subsubsection{The best positive electrode candidates of ARLBS}

Compounds exhibiting high operation potential are obviously most attractive as positive electrode materials and most studies have been devoted to $\mathrm{LiMn}_{2} \mathrm{O}_{4}$, layered $\mathrm{LiMO}_{2}\left(\mathrm{M}: \mathrm{Ni}\right.$, Co or $\mathrm{Mn}$ ) or $\mathrm{LiFePO}_{4}$, with the latter exhibiting a penalty in energy density derived from its lower operation potential. Following seminal work on $\mathrm{LiMn}_{2} \mathrm{O}_{4}$ discussed above, increasing the concentration of the electrolyte from $1 \mathrm{M}$ to $5 \mathrm{M} \mathrm{LiNO}_{3}$ $(\mathrm{pH} \sim 5)$ appeared as a way to improve cycling performance, while at the same time inducing higher ionic conductivity and hence power capability. Indeed, increasing the $\mathrm{pH}$ can diminish the degree of $\mathrm{H}^{+}$coinsertion with $\mathrm{Li}^{+}$as well as $\mathrm{Li}^{+} / \mathrm{H}^{+}$exchange. Interestingly, partial substitution of $\mathrm{Mn}$ by other cations was shown to also result in improved performance, which was attributed to the decreasing amount of the $\mathrm{Mn}^{3+}$ Jahn-Teller ions, mitigating the extent of the $\mathrm{Mn}^{2+}$ dissolution of the positive electrode material at the interface with the electrolyte through the disproportionation reaction $2 \mathrm{Mn}^{3+} \rightarrow \mathrm{Mn}^{4+}+\mathrm{Mn}^{2+}$ sol. Despite the penalty in the energy density (lower amount of $\mathrm{Mn}^{3+}$ ions available to be oxidized), significant improvements in cycle life were achieved and 4000 cycles demonstrated for $\mathrm{LiAl}_{0.10} \mathrm{Mn}_{1.90} \mathrm{O}_{4}$ in $5 \mathrm{M} \mathrm{LiNO}_{3}$ electrolyte at a cycling rate of $1000 \mathrm{~mA} / \mathrm{g}$ (i.e. 9C) [24]. 
Co-intercalation of protons with $\mathrm{Li}^{+}$is also an issue for layered oxides such as $\mathrm{LiCoO}_{2}$ and $\mathrm{LiNi}_{1 / 3} \mathrm{Mn}_{1 / 3} \mathrm{Co}_{1 / 3} \mathrm{O}_{2}$ [23]. $\mathrm{H}^{+}$ions bond to oxygen from the crystal lattice forming $\mathrm{OH}^{-}$groups which hinder diffusion of $\mathrm{Li}^{+}$ions from one octahedral site to another, as stabilized in the intermediate tetrahedral sites in the interslab space. Proton co-intercalation can be mitigated through the use of concentrated electrolytes and increasing the $\mathrm{pH}$. The dissociation of $\mathrm{LiNO}_{3}$ (and other salts used in aqueous battery electrolytes such as $\mathrm{LiOH}$ and $\mathrm{Li}_{2} \mathrm{SO}_{4}$ ) is so high in water that very high concentrations can be reached without being detrimental to the electrolyte viscosity, and thus no issues arise related to the impregnation of the electrodes and to the kinetics of the intercalation and de-intercalation reactions, as is the case in organic Li-ion batteries. Note that increasing the salt concentration does also result in a decrease of freezing point of the electrolyte, and thus widen the practical temperature operation range,

In contrast, the co-intercalation of $\mathrm{H}^{+}$is thermodynamically unfavorable in $\mathrm{LiFePO}_{4}$ as it would require severe distortion of all the coordination polyhedra $\mathrm{FeO}_{6}$ and $\mathrm{PO}_{4}$ [25]. Partial solubility of $\mathrm{LiFePO}_{4}$ is observed in basic electrolytes in the presence of oxygen, either present as traces or produced by water decomposition upon the operation of the battery, with the formation of $\mathrm{Fe}_{2} \mathrm{O}_{3}\left[\mathrm{Fe}^{2+}+2 \mathrm{OH}^{-}+1 / 4 \mathrm{O}_{2} \rightarrow 1 / 2\right.$ $\mathrm{Fe}_{2} \mathrm{O}_{3}+\mathrm{H}_{2} \mathrm{O}$ ] [26]. These side reactions can be reduced via carbon-coating which stabilizes the surface even in the presence of $\mathrm{O}_{2}$ and at $\mathrm{pH}$ 13. It was shown that by eliminating oxygen, adjusting the $\mathrm{pH}$ values of the electrolyte below 8 (Fig. 2), and using carbon-coatings, cells using $\mathrm{LiFePO}_{4}$ and $\mathrm{LiTi}_{2}\left(\mathrm{PO}_{4}\right)_{3}$ (as positive and negative electrode materials respectively) exhibited excellent stability with a capacity retention over $90 \%$ after 1000 cycles at a rate of $6 \mathrm{C}$, and of $85 \%$ after 50 cycles even at a low current rate $(\mathrm{C} / 8)$ in $1 \mathrm{M}$ $\mathrm{Li}_{2} \mathrm{SO}_{4}$ electrolyte [27].

\subsubsection{The challenging negative electrodes of ARLBS}

$\mathrm{LiB}$ negative electrode materials such as graphite or silicon cannot be used in ARLBs as they exhibit too low operation potentials to be stable within the water electrochemical stability window. Oxides and phosphates rich in vanadium or in titanium have thus been widely studied, as they are those exhibiting the lowest operation potential while being at the same time stable in water (Fig. 2 and Table 2). Unfortunately, all of them exhibit low ionic and electronic conductivity and thus induce a penalty in power performance.

A problem of dissolution (i.e. corrosion) was identified for $\mathrm{V}^{5+} \mathrm{O}_{2}, \mathrm{LiV}^{5+}{ }_{3} \mathrm{O}_{8}$ and $\mathrm{LiV}^{4+, 5+}{ }_{2} \mathrm{O}_{5}$. The use of coated electrode materials and of saturated electrolytes to reduce their content in free water molecules and oxygen, and thus their reactivity, were considered to solve such issues, as discussed above for $\mathrm{LiFePO}_{4}$. Nevertheless, maintaining the solvent free of oxygen all along the life of the battery is not obvious as some positive electrode materials (such as layered $\mathrm{LiMO}_{2}$ ) are metastable and can release oxygen during oxidation at high voltage, especially above room temperature. The stability of $\mathrm{VO}_{2}$ is also improved through coating with carbon [28] or even polypyrrole. [29] Alternatively, good electrochemical performances were obtained using $\mathrm{H}_{2} \mathrm{~V}_{3} \mathrm{O}_{8}$ nanowires as electrode materials despite only $70 \%$ of capacity retention after 50 cycles at a current rate of $\sim \mathrm{C}$ in $5 \mathrm{M} \mathrm{LiNO}_{3}+0.001 \mathrm{M} \mathrm{LiOH}$ aqueous electrolyte [30]. $\mathrm{H}_{2} \mathrm{~V}_{3} \mathrm{O}_{8}$ was shown to exhibit higher electronic conductivity than $\mathrm{LiV}_{3} \mathrm{O}_{8}$ due to the mixed valence state of vanadium $\left(1 \mathrm{~V}^{4+}: 2 \mathrm{~V}^{5+}\right)$ and also a better structural stability upon $\mathrm{Li}^{+}$insertion and reinsertion thanks to the presence of $\mathrm{H}_{2} \mathrm{O}$ playing the role of pillars within the structure. However, the cycle life of cells using vanadium oxides as negative electrodes remains still limited. With respect to titanium containing phases, the pyrophosphate $\mathrm{TiP}_{2} \mathrm{O}_{7}$ and the NASICON phase $\mathrm{LiTi}_{2}\left(\mathrm{PO}_{4}\right)_{3}$ have deserved most attention delivering initial capacities close to $100 \mathrm{mAh} / \mathrm{g}$, the formation of a carbon coating being also compulsory for their chemical stabilization upon cycling [31]. 
Overall, the development of a suitable negative electrode material remains the main challenge in ARLBs, as none of the alternatives suggested to date are able to perform more than 100 cycles at a rate below $10 \mathrm{C}$ while retaining an acceptable capacity. To overcome this issue, activated carbon (typically used in supercapacitors) was proposed as a negative electrode (see Table 2) [32, 33] to build t hybrid electrochemical supercapacitors which exhibit high power rates to the expense of limited capacity.

As an alternative approach, aqueous solution of polysulfides (in the forms of $\mathrm{K}_{2} \mathrm{~S}_{\mathrm{x}}$ or $\mathrm{Na}_{2} \mathrm{~S}_{5}$ ) were also proposed as negative electrodes for both aqueous electrolyte $\mathrm{Li}$ and $\mathrm{Na}$-ion batteries with an average voltage being close to $-0.5 \mathrm{~V}$ vs SHE $\left[\mathrm{S}_{2}{ }^{2-}+2 \mathrm{H}_{2} \mathrm{O}+2 \mathrm{e}^{-} \leftrightarrow 2 \mathrm{HS}^{-}+2 \mathrm{OH}^{-}\right][34,35]$. Since the electroactive material is dissolved in the electrolyte (so called anolyte), it needs to be separated from the positive electrodes, which makes the cell architecture somewhat different. Indeed, either Li-ion conductive glass membrane or ionselective polymer membrane is needed to prevent migration of the polysulfides from the negative electrode to the positive electrode during the battery operation [36]. Proof of concept for this system was given using $\mathrm{LiMn}_{2} \mathrm{O}_{4}, \mathrm{NaFePO}_{4}$ or $\mathrm{Na}_{0.44} \mathrm{MnO}_{2}$ as positive electrode materials. It is worth to highlight that the redox mechanism for polysulfides in aqueous medium is different from the one taking place in organic electrolytes. While for the latter, a series of polysulfides $\mathrm{Li}_{2} \mathrm{~S}_{\mathrm{x}}(2<\mathrm{x}<8)$ is formed that finally leads to insoluble and insulating $\mathrm{Li}_{2} \mathrm{~S}$, in aqueous systems three main types of chemical species are formed, $\mathrm{H}_{2} \mathrm{~S}(\mathrm{aq}), \mathrm{HS}^{-}$and $\mathrm{S}_{\mathrm{x}}{ }^{2-}$ that are determined by the $\mathrm{pH}$.

\subsection{The Aqueous Rechargeable Na-ion Batteries (ARNBs)}

\subsubsection{The main positive electrodes of ARNBs}

One of the first positive electrode materials proposed for rechargeable aqueous $\mathrm{Na}$-ion batteries was $\mathrm{Na}_{0.44} \mathrm{MnO}_{2}$, exhibiting a tunnel crystal structure described in Fig. 3 [37], with the hybrid concept $\mathrm{Na}_{0.44} \mathrm{MnO}_{2} / 1 \mathrm{M} \mathrm{Na}_{2} \mathrm{SO}_{4}$ aqueous electrolyte / Activated carbon (AC), being also developed and showing very good reversibility [38]. Interestingly, when $\mathrm{Na}_{0.44}\left[\mathrm{Mn}_{1-\mathrm{x}} \mathrm{Ti}_{\mathrm{x}}\right] \mathrm{O}_{2}$ is used as positive electrode using carbon coated NASICON NaTi $2\left(\mathrm{PO}_{4}\right)_{3}$ as the negative electrode and $1 \mathrm{M} \mathrm{Na}_{2} \mathrm{SO}_{4}$ aqueous electrolyte, a very attractive capacity of $76 \mathrm{mAh} / \mathrm{g}$ at an average voltage of $1.2 \mathrm{~V}$ and at a rate of $2 \mathrm{C}$ is achieved [39] and Aquion Energy Ltd. released a commercially energy storage system based on this chemistry. According to the company, (bankrupted in March 2017) these 1.5V batteries could deliver $30 \mathrm{Wh}^{\mathrm{kg}} \mathrm{kg}^{-1}$, with an efficiency of $85 \%$ after 5000 cycles, which is most likely still insufficient for some applications.

Systems using layered $\mathrm{NaMnO}_{2}$ as positive electrode material were also reported to exhibit excellent cycling behavior and high energy density both using activated carbon or carbon coated $\mathrm{NaTi}_{2}\left(\mathrm{PO}_{4}\right)_{3}$ at the negative electrode. For the later, a $2 \mathrm{M} \mathrm{CH}_{3} \mathrm{COONa}$ aqueous electrolyte was used and an energy density of $30 \mathrm{Wh}^{-\mathrm{kg}^{-}}$

${ }^{1}$ (based on the total mass of active materials) was achieved with capacity retention of $75 \%$ after 500 cycles at a $5 \mathrm{C}$ rate [40]. Mn dissolution upon operation is a bottleneck for all Mn-based oxide electrode materials which, as already discussed, can be mitigated tailoring the electrolyte composition. Indeed, $\mathrm{NaMnO}_{2}$ was revealed to be stable upon long range cycling in the $\mathrm{CH}_{3} \mathrm{COONa}$ electrolyte, whereas rapid fading was observed in $\mathrm{Na}_{2} \mathrm{SO}_{4}$ (i.e. only $25 \%$ of the initial capacity was retained after 500 cycles) due to dissolution. Ionic transport in manganese oxides can be improved by tuning composition, coatings and particle morphology. For instance, the formation of a well ordered hydroxylated interphase at the surface of the layered $\mathrm{Mn}_{5} \mathrm{O}_{8}$ (or $\mathrm{Mn}_{2}{ }_{2} \mathrm{Mn}_{3}{ }_{3} \mathrm{O}_{8}$ ) was shown to inhibit the oxygen evolution reactions at $3 \mathrm{~V}$. 
More recently, a few polyanionic compounds have been also considered as positive electrode materials for ARNBs: $\mathrm{Na}_{2} \mathrm{Fe}^{\mathrm{II}} \mathrm{P}_{2} \mathrm{O}_{7}$ [41, 42], $\mathrm{Na}_{3} \mathrm{~V}^{\mathrm{III}}{ }_{2}\left(\mathrm{PO}_{4}\right)_{3}$ [43], $\mathrm{NaV}^{\mathrm{III}} \mathrm{PO}_{4} \mathrm{~F}$ [44] and $\mathrm{NaFe}^{\mathrm{II}} \mathrm{PO}_{4}$ [45]. Amongst them, the olivine $\mathrm{NaFePO}_{4}$ prepared by chemical delithiation of carbon-coated $\mathrm{LiFePO}_{4}$ has the highest theoretical capacity and operates at $2.9 \mathrm{~V}$ vs. $\mathrm{Na}^{+} / \mathrm{Na}$, this value lying within the electrolyte stability window and allowing thus cycling at lower rates. Full cell batteries were built with $\mathrm{NaTi}_{2}\left(\mathrm{PO}_{4}\right)_{3}$ as negative electrode, which delivered $0.6 \mathrm{~V}$ and $70 \mathrm{mAh} / \mathrm{g}$.

The Prussian Blue Analogues have also been tested as positive electrode materials for rechargeable aqueous Na-ion batteries, especially the copper, nickel and cobalt hexacyanoferrates (NaMHCF, for $\mathrm{Na}_{x} \mathrm{M}^{\mathrm{II}}\left[\mathrm{Fe}(\mathrm{CN})_{6}\right]_{y} \cdot \mathrm{zH}_{2} \mathrm{O}$ with $\mathrm{x} \leq 2, \mathrm{y} \leq 1$, and $\left.\mathrm{M}=\mathrm{Cu}, \mathrm{Ni}, \mathrm{Co}\right)$. Their structures are similar to that of the $\mathrm{ABX}_{3}$ perovskite, a three-dimensional framework with large interstitial spaces for the alkali, and possible cation vacancies $(\mathrm{y}<1)$ as well as inserted water molecules $(\mathrm{z}>0)$. Full aqueous Na-ion batteries were built using the copper hexacyanoferrate at the positive electrode, $\mathrm{NaTi}_{2}\left(\mathrm{PO}_{4}\right)_{3}$ as the negative electrode, and $1 \mathrm{M}$ $\mathrm{Na}_{2} \mathrm{SO}_{4}$ aqueous electrolyte. These cells were shown to deliver a voltage of $1.4 \mathrm{~V}$ and a specific energy of $48 \mathrm{Wh} / \mathrm{kg}$ based on the total weight of the active electrode materials, which is higher than the one mentioned above for the concept developed by Aquion Technology. This system involves the redox couple $\mathrm{Fe}^{\mathrm{II}} / \mathrm{Fe}^{\mathrm{III}}$ and exhibits an high capacity and cyclability at high rate, with $88 \%$ of capacity retention over 1000 cycles at 10C [46]. That kind of chemistry is particularly interesting since the electrode materials and the electrolyte are abundant and low cost. Playing with the composition and the synthesis conditions allows to minimize the amount of $\mathrm{Fe}^{\mathrm{II}}$ vacancies (or of $\mathrm{M}^{\mathrm{II}}$ vacancies, those $\mathrm{M}^{\mathrm{II}}$ ions being the redox centers) and to maximize the content in sodium in the structure, in order to optimize the reversible capacity. Improved performance was recently reported for nanosized $\mathrm{Na}_{2} \mathrm{Co}^{\mathrm{II}} \mathrm{Fe}^{\mathrm{II}}(\mathrm{CN})_{6}$ as it was shown to be perfectly stoichiometric (i.e. with $\mathrm{Na} / \mathrm{M}^{\mathrm{II}}=$ 1) (Fig. 4) [47]. When used in a full cell $\mathrm{Na}_{2} \mathrm{CoFe}(\mathrm{CN})_{6} / \mathrm{NaTi}_{2}\left(\mathrm{PO}_{4}\right)_{3}$, appealing performances were confirmed with a high voltage of $1.7 \mathrm{~V}$, a high energy density of $67 \mathrm{Wh} / \mathrm{kg}$ (based on the total weight of active materials) after 200 cycles. Interestingly, Natron Energy and Sharp from USA, Novasis-e from Canada and Altris from Sweden developed ARNBs based on Prussian Blue Analogues.
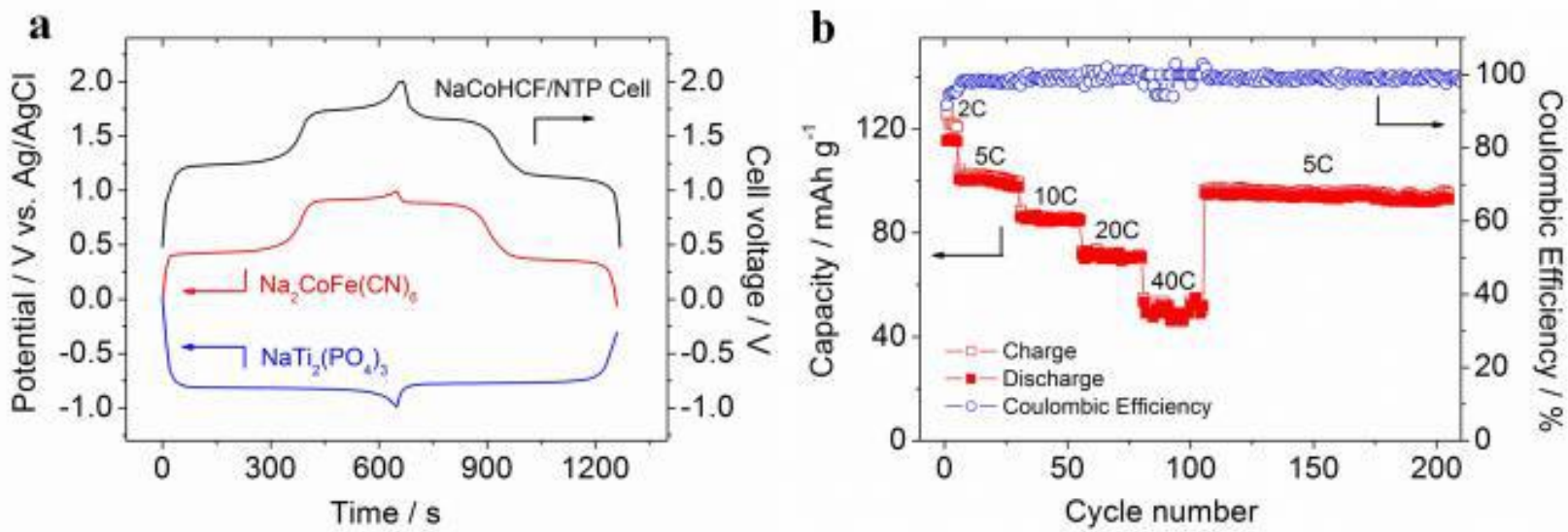

Figure 4: The electrochemical performances of the full cell $\mathrm{Na}_{2} \mathrm{CoFe}(\mathrm{CN})_{6} / / \mathrm{NaTi}_{2}\left(\mathrm{PO}_{4}\right)_{3}$. The cell was constructed such as it is positive-limited with a slight excess of negative electrode material. (a) The charge/discharge curves of the full cell (black line), of the cobalt hexacyanoferrate (NaCoHCF) (red line) and of the NASICON phase $\mathrm{NaTi}_{2}\left(\mathrm{PO}_{4}\right)_{3}$ (blue line) (vs. $\mathrm{Ag} / \mathrm{AgCl}$ ) at a high rate of $5 \mathrm{C}$. (b) Rate capability 
and cycle performance of the full cell at various $\mathrm{C}$ rates, the capacity was calculated based on the positive electrode mass only [47].

\subsubsection{The limited number of negative electrodes of ARNBs}

As highlighted in Fig. 2, mainly two V-based and Ti-based $\left(\mathrm{Na}_{2} \mathrm{~V}^{5+}{ }_{6} \mathrm{O}_{16} \cdot \mathrm{nH}_{2} \mathrm{O}\right.$ and $\mathrm{NaTi}^{4+}{ }_{2}\left(\mathrm{PO}_{4}\right)_{3}$ respectively) compounds exhibit suitable operation potentials to be considered as possible negative electrodes ifor ARNBs, with the latter having deserved most attention (Fig. 5) [48]. Similar strategies to those discussed above for ARLBs were applied to optimize $\mathrm{NaTi}_{2}\left(\mathrm{PO}_{4}\right)_{3}$, involving the control of the particle size and morphology and the formation of a carbon coating. Nevertheless, despite significant improvements, the long range cycling performance is far from being optimized [49].

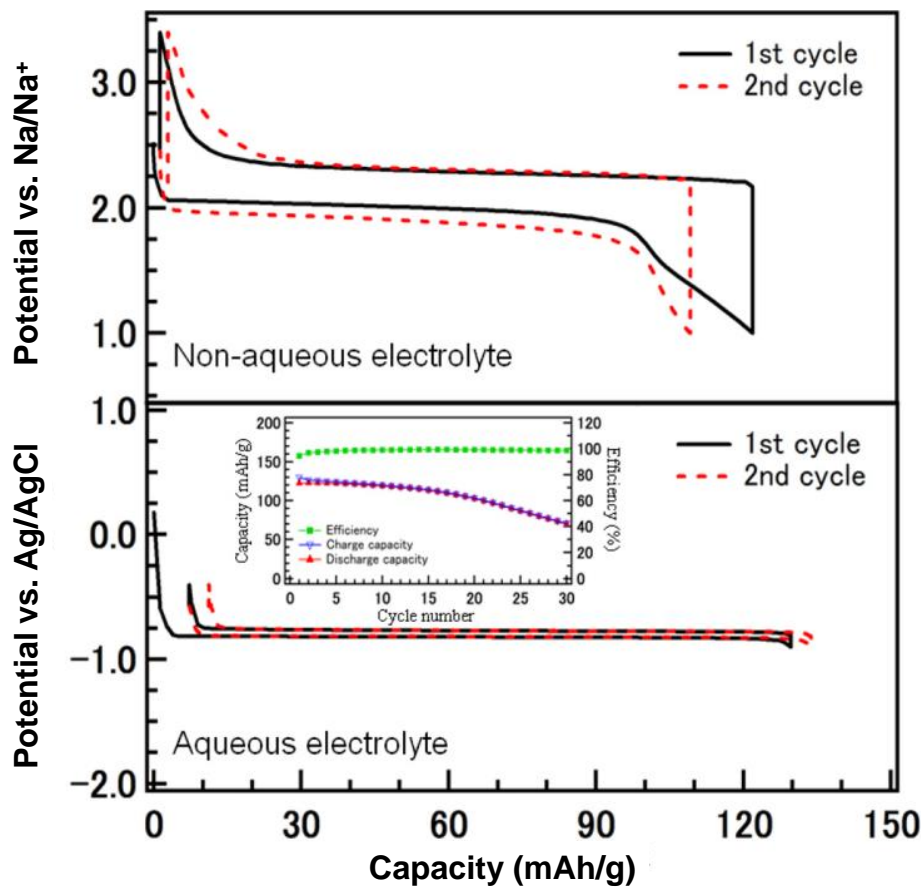

Figure 5: Electrochemical curves obtained at a rate of $2.0 \mathrm{~mA} / \mathrm{cm}^{2}$ during the first and second cycles of a non-aqueous sodium cell $\mathrm{NaTi}_{2}\left(\mathrm{PO}_{4}\right)_{3} / / \mathrm{Na}$ (top) and of an aqueous cell $\mathrm{NaTi}_{2}\left(\mathrm{PO}_{4}\right)_{3} / / \mathrm{Zn}$ (bottom). The dependence of the capacity on the cycle number in the aqueous electrolyte is given in inset for $\mathrm{NaTi}_{2}\left(\mathrm{PO}_{4}\right)_{3}$. The comparison of the two electrochemical curves reveal a drastic decrease of the polarization in aqueous electrolyte, the high ionic conductivity resulting in a low/negligible internal resistance [48].

Interestingly, a symmetric Na-ion battery was demonstrated; with the NASICON phase $\mathrm{Na}_{3} \mathrm{Mn}^{\mathrm{II}} \mathrm{Ti}^{\mathrm{iV}}\left(\mathrm{PO}_{4}\right)_{3}$ at both the positive and negative electrodes. Its specific composition enables operation through two different redox couples $\mathrm{Ti}^{4+} / \mathrm{Ti}^{3+}$ and $\mathrm{Mn}^{3+} / \mathrm{Mn}^{2+}$ working on the negative side for the first and on the positive side for the second. This symmetric cell exhibits a voltage plateau centered at about $1.4 \mathrm{~V}$ with a stable cycle performance and good rate capability. The energy density delivered by this aqueous system is about 40 $\mathrm{Wh} / \mathrm{kg}$ (based on the total weight of the active electrode materials), which is comparable to or higher than 
the conventional aqueous rechargeable batteries and the recently developed aqueous sodium-ion batteries [50].

\section{Batteries Based on Multivalent Ions}

Two fundamental factors need to be taken into account when developing batteries enlisting ion intercalation reactions in aqueous electrolytes: $i)$ the ionic radii and ii) the charge density of the ions. The ionic radius of the $\mathrm{Zn}^{2+}$ ion is $0.74 \AA$, which is very close to that of $\mathrm{Li}^{+}$ions $(0.76 \AA$ ) but its higher charge to radius ratio induces a much higher polarizing character which may limit its migration dynamics. Starting from Volta's experiments in the early 1800s (Fig. 1), zinc has received great attention since it is the most electropositive metal that is relatively stable in aqueous media and has practical benefits (low cost, high abundance, environmental benignity and an already existing long tradition of $\mathrm{Zn}$ recycling). Zn-based batteries already exist at the marketplace as primary (single-use or non-rechargeable) alkaline $\mathrm{Zn}-\mathrm{MnO}_{2}$ or $\mathrm{Zn}$ /air batteries. Alkaline $\mathrm{Zn}-\mathrm{MnO}_{2}$ batteries exhibit a potential of 1.55 - $1.8 \mathrm{~V}$, depending on the $\mathrm{MnO}_{2}$ polymorph used as positive electrode and on the electrolyte, and have become dominant in primary battery chemistry. The halfcell reaction occurring at the positive electrode is given below, it implies a $\mathrm{H}^{+}$insertion in $\mathrm{MnO}_{2}$ in an alkaline solution with thus the partial reduction of $\mathrm{Mn}^{4+}$ in $\mathrm{MnO}_{2}$ to $\mathrm{Mn}^{3+}$ forming $\mathrm{MnO}_{2-\mathrm{x}}(\mathrm{OH})_{\mathrm{x}}$.

$\mathrm{MnO}_{2}+\mathrm{xH}_{2} \mathrm{O}+\mathrm{xe}^{-} \rightarrow \mathrm{MnO}_{2-\mathrm{x}}(\mathrm{OH})_{\mathrm{x}}+\mathrm{xOH}^{-}$

Early indications of electrochemical activity of oxygen trace back to Van Marum (1801) and Leclanché, when they realized that their $\mathrm{Zn} / \mathrm{C}-\mathrm{MnO}_{2}$ batteries exhibited larger capacities when exposed to air. This observation led to the development of $\mathrm{Zn}$ /air primary batteries in the early $20^{\text {th }}$ century, commercialized for the first time in 1932 and remaining the only commercially available primary metal-air batteries to date, with a theoretical energy density up to about $1.3 \mathrm{kWh} / \mathrm{kg}$.

In contrast, the concept of Zinc-ion batteries (ZIBs) appeared somewhat later with the pioneering work published by Yamamoto [51] in 1986 demonstrating the possibility of using a mild aqueous electrolyte to minimize $\mathrm{Zn}$ dendrite formation and thus to build rechargeable systems. The topic has however received little attention for more than 2 decades. In 2012 Kang et al. demonstrated long cycle life (over 100 cycles) at relatively high current density (6C) for a rechargeable Zinc-ion battery using $\alpha-\mathrm{MnO}_{2}$ at the positive electrode together with zinc at the negative electrode and a mild $\mathrm{ZnSO}_{4}$ or $\mathrm{Zn}\left(\mathrm{NO}_{3}\right)_{2}$ aqueous electrolyte [52]. Afterwards, the numbers of publications on this subject increased steadily every year (Fig. 6a) [53]. The revival of this field has witnessed research focused on both the development of electrode materials and on the understanding of the reaction mechanisms and side reactions, the latter being at the origin of the loss of reversibility and performance.

Zinc ion chemistry in water is rather complex. Contrary to the binding of water molecules with alkali metal ions $\left(\mathrm{Li}^{+} / \mathrm{Na}^{+}\right)$via electrostatic interactions, $\mathrm{Zn}^{2+}$ ion builds much more covalent interaction with water molecules, which is in agreement with the high solvation energy for zinc ion: $\sim 500 \mathrm{kcal} / \mathrm{mole}$ in aqueous solutions. Indeed, assuming six water molecules in the solvation shell of a central zinc ion (Fig. 6b) [54], 
the enthalpy of solvation for one water molecule is $\sim 80 \mathrm{kcal} / \mathrm{mol}$, which corresponds to typical values for covalent $\mathrm{Zn}-\mathrm{O}$ bond formation (70 to $85 \mathrm{kcal} / \mathrm{mol}$ ) [55].

The redox reaction mechanisms for ZIBs are yet under debate, as besides the intercalation/de-intercalation of zinc ions, side reactions involving protons/water as those mentioned in the ARLBs and ARNBs are even more likely in this system, as a result of the lower mobility expected for divalent ions. These reactions can take place simultaneously to a greater or lesser extent depending on the experimental conditions (involving composition of electrodes/electrolyte but also battery operation related parameters such as current and potential).
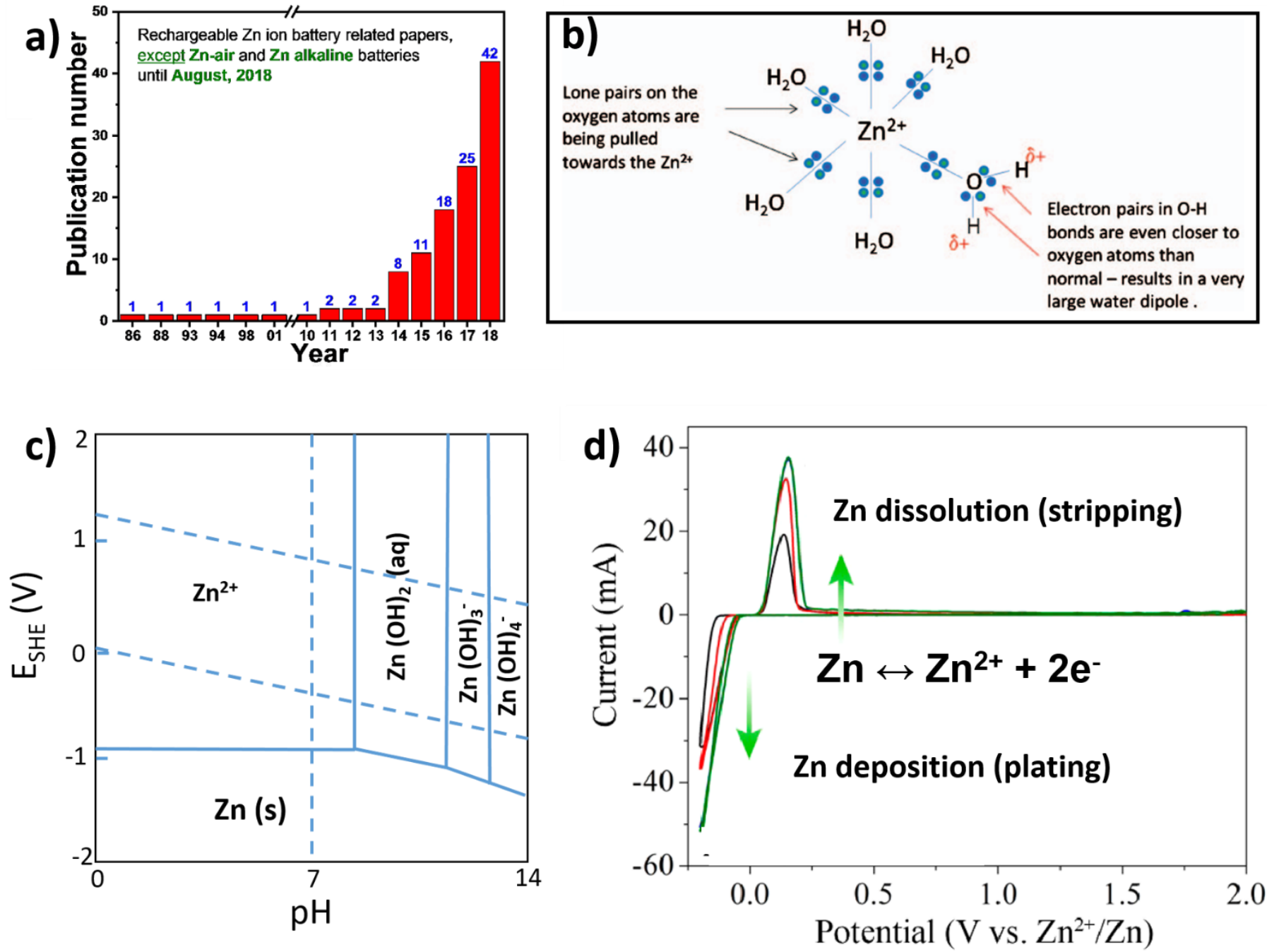

Figure 6: a) The number of publications up to August 2018 [53] b) Illustration of the bonding between $\mathrm{Zn}^{2+}$ and the first shell water molecules [54] c) Pourbaix diagram of $\mathrm{Zn}$ in aqueous solution from [56], d) a typical stripping and plating of $\mathrm{Zn}$ metal anode. 


\subsection{Negative Electrodes in Zn-ion Batteries}

Herein, the imperative question is: what strategy could be used to promote rechargeability in the $\mathrm{Zn}$ based batteries after they have been used as primary alkaline $\mathrm{Zn} / \mathrm{MnO}_{2}$ or $\mathrm{Zn} /$ air cells for a long time? As depicted in the Pourbaix diagram (Fig. 6c), in primary alkaline batteries there is precipitation of $\mathrm{ZnO}$ or $\mathrm{Zn}(\mathrm{OH})_{2}$ in electrolytes with $\mathrm{pH}$ values close to 13 [55-57] and the discharge product is the zincate ion $\left(\mathrm{Zn}(\mathrm{OH})_{4}{ }^{2-}\right)$ which ultimately precipitates as $\mathrm{ZnO}$ [57]. In basic solutions, the $\mathrm{Zn}$ anode exhibits various technical problems for rechargeability including: i) non-uniform $\mathrm{Zn}$ re-plating during the charge process with the formation of dendrites resulting in short-circuits of the cell, ii) high self-discharge related to $\mathrm{Zn}$ corrosion, and iii) limited power density. In neutral or mildly acidic electrolytes, high reversibility stripping/plating of $\mathrm{Zn}$ can be achieved according to the reaction $\left[\mathrm{Zn} \leftrightarrow \mathrm{Zn}^{2+}+2 \mathrm{e}^{-}\right]$(Fig. 6d). In more acidic electrolytes, severe corrosion of the $\mathrm{Zn}$ metal negative electrode occurs, and these should thus be avoided. As a consequence of these requirements, the most common salts used to prepare electrolytes with $\mathrm{pH}$ in the optimum range (4.0 to 6.0) are $\mathrm{ZnSO}_{4}, \mathrm{Zn}\left(\mathrm{NO}_{3}\right)_{2}, \mathrm{Zn}\left(\mathrm{CH}_{3} \mathrm{COO}\right)_{2}, \mathrm{Zn}\left(\mathrm{ClO}_{4}\right)_{2}, \mathrm{Zn}\left(\mathrm{CF}_{3} \mathrm{SO}_{3}\right)_{2}$ or $\mathrm{ZnCl}_{2}$.

In general, the $\mathrm{Zn}$ metal negative electrode used in the aqueous rechargeable ZIBs is in the form of $\mathrm{Zn}$ metal foil, $\mathrm{Zn}$ powder or $\mathrm{Zn}$ paste, and dendritic metal growth is often observed upon electrodeposition. After continuous charging and discharging steps, small dendrite tips amplify via preferential deposition on the surfaces located especially at the edge of the electrode. Their growth rate is highly dependent on the current applied, and when large, they may penetrate the separator and result in the short circuit of the cells. The most effective methods to struggle against dendritic growth involve the use of different $\mathrm{Zn}$ electrode architectures, the protection by coating layers as well as the use of electrolyte additives. The architectures of the $\mathrm{Zn}$ electrode have been modified through the design of a sponge like three-dimensional porous monoliths to suppress dendrite formation [58] or of $\mathrm{Zn} / \mathrm{C}$ composites with graphite, carbon nanotubes, activated carbons [59] to lower the charge transfer resistance and improve the reaction kinetics and electrochemical performances [60,61]. Additionally, the coating of the $\mathrm{Zn}$ negative electrode with nano$\mathrm{CaCO}_{3}$-coated has been shown to inhibit the dendritic growth [62]. Schematic illustrations of morphology evolution for bare and nano- $\mathrm{CaCO}_{3}$-coated $\mathrm{Zn}$ foils during $\mathrm{Zn}$ stripping/plating cycling is shown in Fig. 7. During the successive charge-discharge steps, dendrites/protrusions firstly nucleate on the small-sized nanopores of the nano- $\mathrm{CaCO}_{3}$-coating, grow (plating), and then are electrodissolved (stripping). Thus, the nano- $\mathrm{CaCO}_{3}$-coating results in a position-selected and bottom-up $\mathrm{Zn}$ deposition process at the interface between the metal foil and the coating layer, rather than a preferential deposition on the tips of $\mathrm{Zn}$ protrusions/dendrites. Similar effects can be observed using oxides (i.e. $\mathrm{SiO}_{2}, \mathrm{AlO}_{3}$ etc.). Despite rather similar galvanostatic electrochemical signatures (Fig. 7b), longer term stability is obtained with the nano$\mathrm{CaCO}_{3}$-coated sample resulting in a $180 \mathrm{mAh} / \mathrm{g}$ discharge capacity over 1000 cycles while with bare $\mathrm{Zn}$ only delivers $120 \mathrm{mAh} / \mathrm{g}$ (Fig. 7c). Furthermore, in order to produce distinctively different crystallographic zinc orientation and surface textures, organic electrolyte additives such as sodium dodecyl sulfate, thiourea, polyethylene-glycol and cetyltrimethylammonium bromide have been used. These synthetic zinc electrodeposits were shown to exhibit 6 to 30 times lower corrosion when used as negative electrodes in aqueous rechargeable $\mathrm{Zn}$-ion batteries [63]. In any case, such additives need to be tested in a full cell configuration to ensure their compatibility with the positive electrodes and not to inhibit the $\mathrm{Zn}^{2+}$ ion migration processes. 

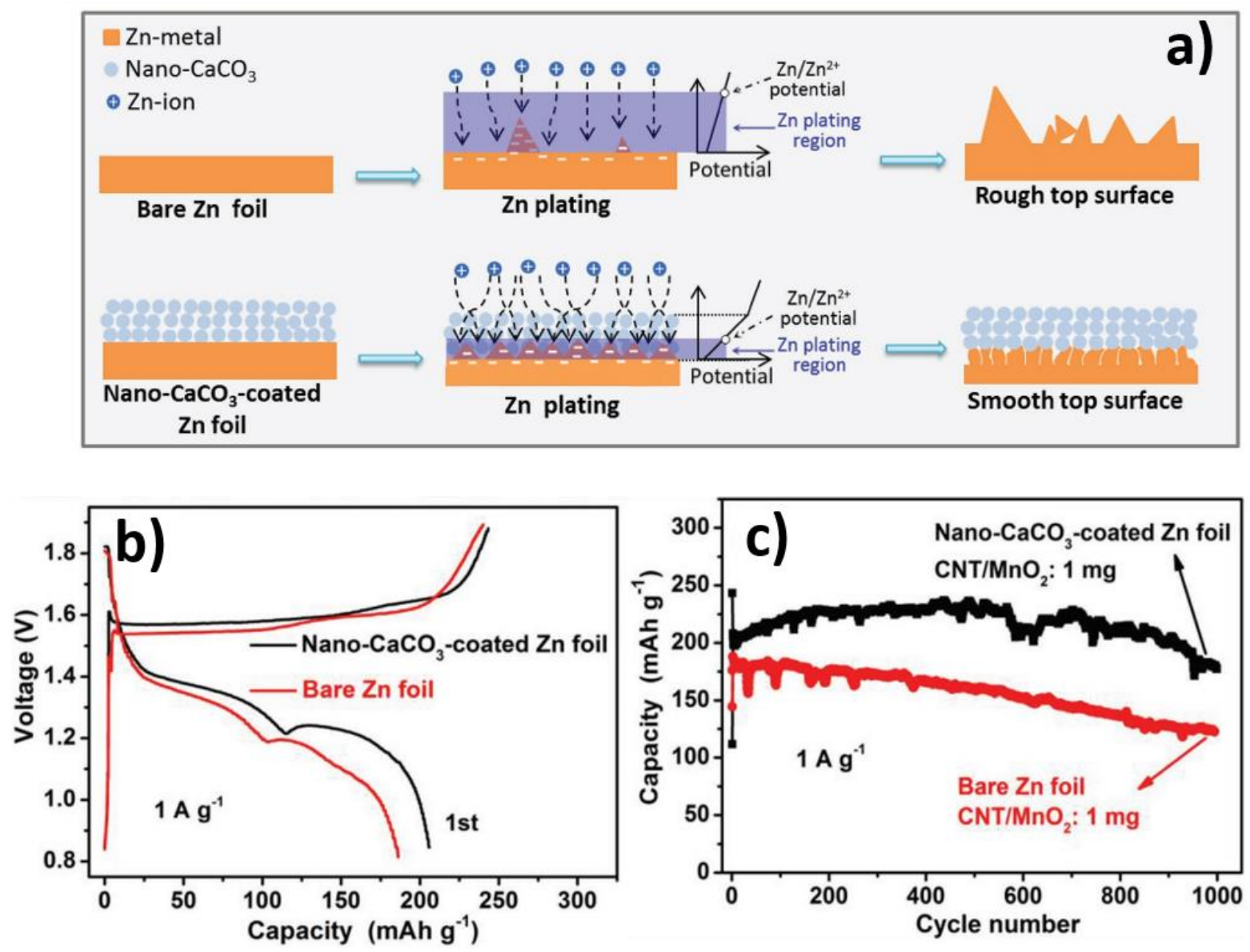

Figure 7: a) Schematic illustrations of morphology evolution for bare and nano- $\mathrm{CaCO}_{3}$-coated $\mathrm{Zn}$ foils during Zn stripping/plating cycling, b) Galvanostatic charge-discharge curves of the first cycle, and c) galvanostatic cycling performance of $\mathrm{Zn}\left|\mathrm{ZnSO}_{4}+\mathrm{MnSO}_{4}\right| \mathrm{CNT} / \mathrm{MnO}_{2}$. Each battery used a $\mathrm{CNT} / \mathrm{MnO}_{2}$ positive electrode, a glass fiber separator wetted with a $3 \mathrm{M} \mathrm{ZnSO}_{4}+0.1 \mathrm{M} \mathrm{MnSO}_{4}$ aqueous electrolyte and a bare or nano- $\mathrm{CaCO}_{3}$-coated $\mathrm{Zn}$ negative electrode [62].

\subsection{Positive Electrodes in Zn-ion Batteries}

Besides manganese oxides (used in the primary concepts), the quest for ZIB positive electrode materials is, as in the case of ARLBs and ARNBs, also inspired on the existing knowledge developed for LiBs. Indeed, electrode materials which exhibit open structures able to reversibly insert/de-insert ions could, a priori, be employed also for multivalent ions (Fig. 2). These include Mn and V-based oxides, Prussian blue analogues and also Chevrel phases, organic (quinone-based for instance) or polyanionic ( $\mathrm{LiFePO}, \mathrm{Na}_{3} \mathrm{~V}_{2}\left(\mathrm{PO}_{4}\right)_{2}$ etc.) compounds.

\subsubsection{Mn-based oxides}

$\mathrm{MnO}_{2}$ is characterized by a high theoretical capacity $\left(\sim 308 \mathrm{mAh} / \mathrm{g}\right.$ for the exchange of $0.5 \mathrm{~mol}$ of $\mathrm{Zn}^{2+}$ per $1 \mathrm{~mol}$ of $\mathrm{MnO}_{2}$ and concomitant reduction of manganese to $\mathrm{Mn}^{2+}$ ) and can exhibit different polymorphs 
(Fig. 8) [64] such as $\alpha-\mathrm{MnO}_{2}, \beta-\mathrm{MnO}_{2}, \gamma-\mathrm{MnO}_{2}, \mathrm{R}-\mathrm{MnO}_{2}, \delta-\mathrm{MnO}_{2}$ or $\lambda-\mathrm{MnO}_{2}$, depending on the type of linkage (via edges and/or corners) between the octahedral unit $\left[\mathrm{MnO}_{6}\right]$ in which $\mathrm{Mn}^{4+}$ is surrounded by six oxygen neighbours. Tunnel-type $\mathrm{MnO}_{2}$ polymorphs (i.e. $\alpha-\mathrm{MnO}_{2}, \beta-\mathrm{MnO}_{2}, \gamma-\mathrm{MnO}_{2}, \mathrm{R}-\mathrm{MnO}_{2}$ ) are arranged by corner sharing $\mathrm{MnO}_{6}$ octahedra with different tunnel sizes as depicted in Fig. 8a. The layered-type $\delta$ $\mathrm{MnO}_{2}$ polymorph is formed by the stacking of slabs made of edge-sharing $\mathrm{MnO}_{6}$ octahedra, with the presence of water molecules or other cations to stabilize the framework. Depending on the nature of the inserted species, $\delta-\mathrm{MnO}_{2}$ is called birnessite, buserite, chalcophanite or vernadite (Fig. 8b). The spinel-type $\lambda-\mathrm{MnO}_{2}$ polymorph is a, oxygen cubic-closed packed three dimensional framework with interlinked channels for diffusion (Fig. 8c).

Up to now, the redox mechanism was only studied in detail for the tunnel-type $\alpha-\mathrm{MnO}_{2}$ polymorph, and its understanding still remains rather confusing with contradictory results being sometimes reported. Indeed, due to the complexity of the reactions involved, these contradictions probably come from the different conditions of study, in situloperando or ex situ. Moreover, as well known for other electrode material chemistries and battery technologies, the control of the particle size and shape strongly influence the transport kinetics and thus significantly impacts the electrochemical performance of $\alpha-\mathrm{MnO}_{2}$. The $\mathrm{pH}$ of the aqueous electrolyte which varies with the type of salts and their concentration is also expected to impact the electrochemical mechanism and the extent to which dissolution and reactions involving protons/water take place. Indeed, as depicted in the Pourbaix diagram of $\mathrm{MnO}_{2}$ (Fig. 8d) [65], between 0.0 and $1.2 \mathrm{~V}$ (vs saturated calomel electrode ( $\mathrm{SCE}$ ) ) and at $\mathrm{pH}$ values below 7, solid $\mathrm{MnO}_{2}$ electrode is prone to dissolve generating $\mathrm{Mn}^{2+}$ species, while it is stable above $1.2 \mathrm{~V}$. Thus, not only the electrolyte $\mathrm{pH}$ but also the cell's cycling conditions (i.e. upper and lower cut-off voltages values, applied current etc.) play an important role. Moreover, after a series of reaction steps, the large stress can cause the gradual collapse of the tunnels or layers upon electrochemical cycling. 
a) Tunnel-like structure
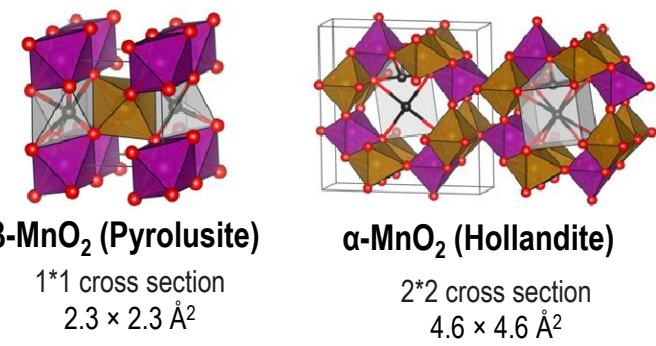

a-MnO $\mathrm{Mnollandite)}^{2}$

$2 * 2$ cross section $4.6 \times 4.6 \AA^{2}$

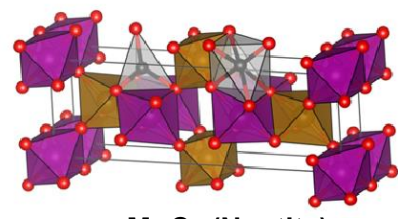

$\mathrm{Y}-\mathrm{MnO}_{2}$ (Nsutite)

$1 * 1$ and $1 * 2$ cross section $2.3 \times 4.6 \AA^{2}$

Intergrowth between $\beta-\mathrm{MnO}_{2}$ and $\mathrm{R}-\mathrm{MnO}_{2}$ Ramdomly arranged

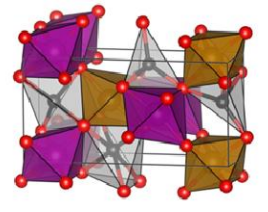

$\mathrm{R}-\mathrm{MnO}_{2}$ (Ramsdellite)

$1 * 1$ and $1 * 2$ cross section $2.3 \times 4.6 \AA^{2}$

Ramdomly arranged b) Layered-like structure

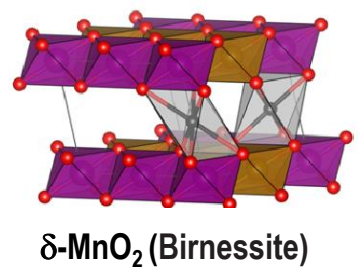

interlayer distance $(\sim 7 \AA)$

\section{C) Spinel structure}

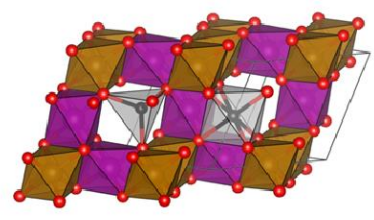

$\Lambda-\mathrm{MnO}_{2}$ (Hausmannite) d)

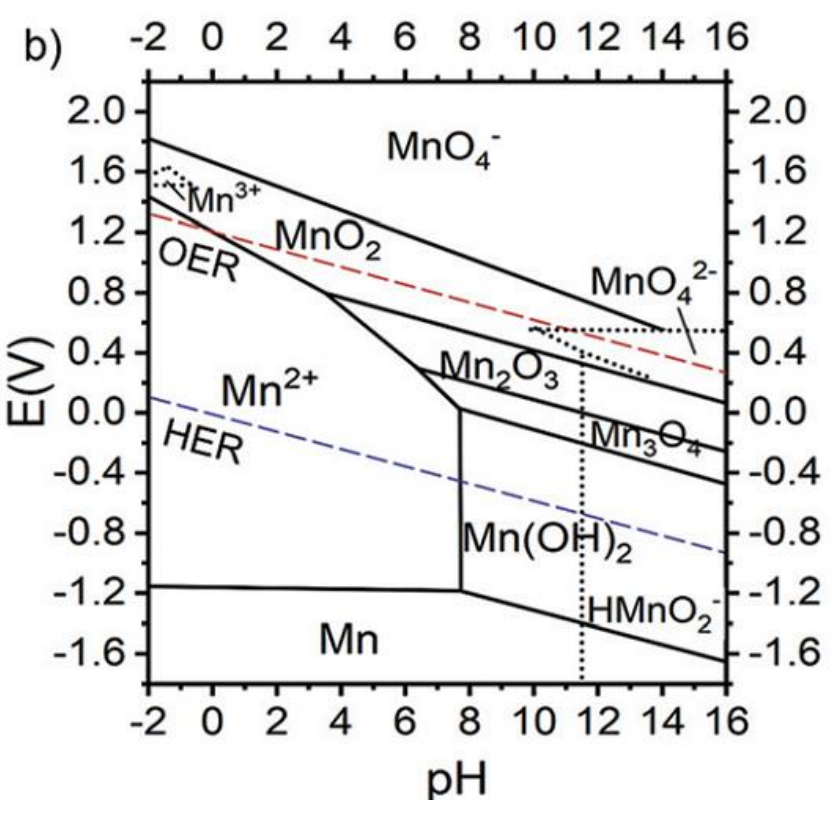

Figure 8: Polyhedral representation of the six Mn oxides reported herein: (a) Tunnel-like including $\alpha, \gamma, \beta$ or $\mathrm{R}-\mathrm{MnO}_{2}$, (b) layered-like $\delta-\mathrm{MnO}_{2}$, (c) spinel-like $\lambda-\mathrm{MnO}_{2}$ [64] The $\mathrm{MnO}_{6}$ octahedra appears as violet or brown, whereas the sites available for insertion of ions are light grey octahedra or tetrahedral, (d) Pourbaix diagram of $\mathrm{MnO}_{2}[65]$

The $\mathrm{Zn}^{2+}$ insertion/extraction reaction has been mostly studied for the $\alpha-\mathrm{MnO}_{2}$ polymorph which has relatively large tunnels with cross sections made of $2 * 2 \mathrm{MnO}_{6}$ octahedra. The reactions taking place at the positive and negative electrodes are depicted below, the global process being: $\mathrm{Zn}+2 \mathrm{Mn}^{4+} \mathrm{O}_{2} \rightarrow \mathrm{ZnMn}^{3+}{ }_{2} \mathrm{O}_{4}$.

Positive: $2 \alpha-\mathrm{Mn}^{4+} \mathrm{O}_{2}+\mathrm{Zn}^{2+}+2 \mathrm{e}^{-} \leftrightarrow \mathrm{ZnMn}^{3+}{ }_{2} \mathrm{O}_{4}$

Negative: $\mathrm{Zn} \leftrightarrow \mathrm{Zn}^{2+}+2 \mathrm{e}^{-}$

$\mathrm{Zn}$-insertion into the host $\alpha-\mathrm{MnO}_{2}$ structure and the formation of $\mathrm{ZnMn}^{3+}{ }_{2} \mathrm{O}_{4}$ were monitored by synchrotron XAS and ex situ XRD experiments, revealing the oxidation of $\mathrm{Mn}^{4+}$ into $\mathrm{Mn}^{3+}$ in agreement with a $\mathrm{Zn} / \mathrm{Mn}$ ratio of 0.52 at the end of the discharge [66]. $\alpha-\mathrm{MnO}_{2}$ nano-rods exhibited an initial discharge capacity of 
$233 \mathrm{~mA} \mathrm{~h} / \mathrm{g}$ at a current density of $83 \mathrm{~mA} / \mathrm{g}$ with nearly $100 \%$ coulombic efficiency over 50 cycles. The formation of $\mathrm{ZnMn}_{2} \mathrm{O}_{4}$ is irreversible, as this phase exhibits large barriers for $\mathrm{Zn}$ migration.

$\mathrm{H}^{+} / \mathrm{H}_{3} \mathrm{O}^{+}$intercalation/extraction: As in the case of primary alkaline cells, the $\mathrm{MnOOH}$ phase can be formed upon reduction through the proton insertion into the lattice $\left[\mathrm{Mn}^{4+} \mathrm{O}_{2}+\mathrm{H}^{+}+\mathrm{e}^{-} \leftrightarrow \mathrm{Mn}^{3+} \mathrm{OOH}\right]$. This reaction can be accompanied by significant morphological changes, for instance from micrometre-long nanofibers for $\alpha-\mathrm{MnO}_{2}$ to short nanorods for $\mathrm{MnOOH}$ [67]. In this case, further investigation using Scanning/TEM and EDS mapping revealed that zinc was not inserted into the nanofibers but mainly distributed on the flake-like solid. Based on these findings, the authors postulated that during discharge, $\mathrm{H}^{+}$ from the electrolyte converts $\alpha-\mathrm{MnO}_{2}$ to $\mathrm{MnOOH}$, whereas $\mathrm{OH}^{-}$from the electrolyte reacts with $\mathrm{ZnSO}_{4}$ to form $\mathrm{ZnSO}_{4}\left[\mathrm{Zn}(\mathrm{OH})_{2}\right]_{3}$. The overall reaction mechanism being:

Positive: $\mathrm{H}_{2} \mathrm{O} \leftrightarrow \mathrm{H}^{+}+\mathrm{OH}^{-}$

$$
\begin{aligned}
& \mathrm{MnO}_{2}+\mathrm{H}^{+}+\mathrm{e}^{-} \leftrightarrow \mathrm{MnOOH} \\
& 1 / 2 \mathrm{Zn}^{2+}+\mathrm{OH}^{-}+1 / 6 \mathrm{ZnSO}_{4}+\mathrm{x} / 6 \mathrm{H}_{2} \mathrm{O} \leftrightarrow 1 / 6 \mathrm{ZnSO}_{4}\left[\mathrm{Zn}(\mathrm{OH})_{2}\right]_{3} \cdot \mathrm{xH}_{2} \mathrm{O}
\end{aligned}
$$

Negative: $1 / 2 \mathrm{Zn} \leftrightarrow 1 / 2 \mathrm{Zn}^{2+}+2 \mathrm{e}^{-}$

Overall: $\mathrm{MnO}_{2}+1 / 2 \mathrm{Zn}+\mathrm{x} / 6 \mathrm{H}_{2} \mathrm{O}+1 / 6 \mathrm{ZnSO}_{4} \leftrightarrow \mathrm{MnOOH}+1 / 6 \mathrm{ZnSO}_{4}\left[\mathrm{Zn}(\mathrm{OH})_{2}\right]_{3} \cdot \mathrm{xH}_{2} \mathrm{O}$

Phase transformations during operation can also occur. As highlighted for instance by transmission electron microscopy (TEM) diffraction analysis, the tunneled $\alpha-\mathrm{MnO}_{2}$ can be transformed into the layered $\delta-\mathrm{MnO}_{2}$ (Zn-birnessite) during the discharge process involving also partial dissolution of manganese [68]. As discussed before, $\mathrm{Zn}^{2+}$ insertion into $\alpha-\mathrm{MnO}_{2}$ is compensated by the reduction of $\mathrm{Mn}^{4+}$ into $\mathrm{Mn}^{3+}$, known as a Jahn-Teller ion due to its high-spin electronic configuration $\left(\mathrm{d}^{4}=\mathrm{t}_{2 \mathrm{~g}}{ }^{3} \mathrm{~g}^{1}\right)$ and to be rather unstable. Indeed, $\mathrm{Mn}^{3+}$ ions easily undergo disproportionation into $\mathrm{Mn}^{4+}$ and water-soluble $\mathrm{Mn}^{2+}$ leading to the reaction: $2 \mathrm{Mn}^{3+}$ $\rightarrow \mathrm{Mn}^{4+}(\mathrm{s})+\mathrm{Mn}^{2+}(\mathrm{aq})$. This partial dissolution of $\mathrm{Mn}$ leads to cationic reorganization in order to stabilize the framework and thus to the transformation into a layered $\delta-\mathrm{MnO}_{2}$ type structure. It was shown that $\mathrm{Mn}^{2+}$ ions dissolved in the electrolyte participate then, at least partially, in the electrochemical processes during subsequent oxidation. Indeed, $\mathrm{Mn}^{2+}$ ions are reversibly inserted back into the layers to reform the tunneled structure. This point has also been experimentally proven by replacing after the first discharge the electrolyte that contains dissolved $\mathrm{Mn}^{2+}$ ions with a fresh non- $\mathrm{Mn}^{2+}$ ion containing electrolyte: the cell was not able to charge supporting the hypothesis that the dissolution/deposition of $\mathrm{Mn}^{2+}$ ions takes an integral part in the redox reaction mechanism. Apparent contradictory results had been reported in the literature by the same research group [69], with in some cases the formation of the layered $\delta-\mathrm{MnO}_{2}$ structure with co-insertion of two water molecules with $\mathrm{Zn}^{2+}$ ion in the interlayer (known as $\mathrm{Zn}$ buserite; a layered structure with a much larger interlayer distance $(11 \AA)$ ) and in others only one water molecules (known as Zn birnessite, the interlayer distance is $7 \AA$ ). In fact, the first was transformed into the second by the loss of one water molecule during sample preparation (recovery, washing and drying) for ex situ characterizations.

The increase in the $\mathrm{Mn}^{2+}$ ion concentration in the electrolyte during cell discharge is inherently accompanied by a rise in $\mathrm{pH}\left[\mathrm{MnO}_{2}+2 \mathrm{H}_{2} \mathrm{O} \rightarrow \mathrm{Mn}^{2+}+4 \mathrm{OH}^{-}\right]$as observed with in-situ monitoring of the $\mathrm{pH}$ changes during battery operation (Fig. 9d), and it leads to the precipitation of zinc hydroxide sulfate $\mathrm{Zn}_{4}(\mathrm{OH})_{6}\left(\mathrm{SO}_{4}\right) .5 \mathrm{H}_{2} \mathrm{O}$ on the positive electrode as:

$3 \mathrm{MnO}_{2}+8 \mathrm{Zn}^{2+}+2 \mathrm{SO}_{4}{ }^{2-}+16 \mathrm{H}_{2} \mathrm{O}+6 \mathrm{e}^{-} \rightarrow 3 \mathrm{Mn}^{2+}+2 \mathrm{Zn}_{4}(\mathrm{OH})_{6}\left(\mathrm{SO}_{4}\right) \cdot 5 \mathrm{H}_{2} \mathrm{O} \downarrow$

As shown in Fig. 10, this phase disappears when the cell is charged to $1.9 \mathrm{~V}$, in agreement with a precipitation - dissolution process taking place. The partial irreversibility of the $\mathrm{Mn}^{2+}$ dissolution/re- 
insertion being at the origin of the capacity fading, the use of $\mathrm{MnSO}_{4}$ as an additive in the electrolyte was proposed to mitigate this issue [67]. Indeed, the additional $\mathrm{Mn}^{2+}$ source in the electrolyte decreases the degree of manganese dissolution by shifting the $\mathrm{MnO}_{2}(\mathrm{~s}) / \mathrm{Mn}^{2+}(\mathrm{aq})$ equilibrium and as a consequence prevents the formation of basic zinc sulfate on the electrode surface [53].
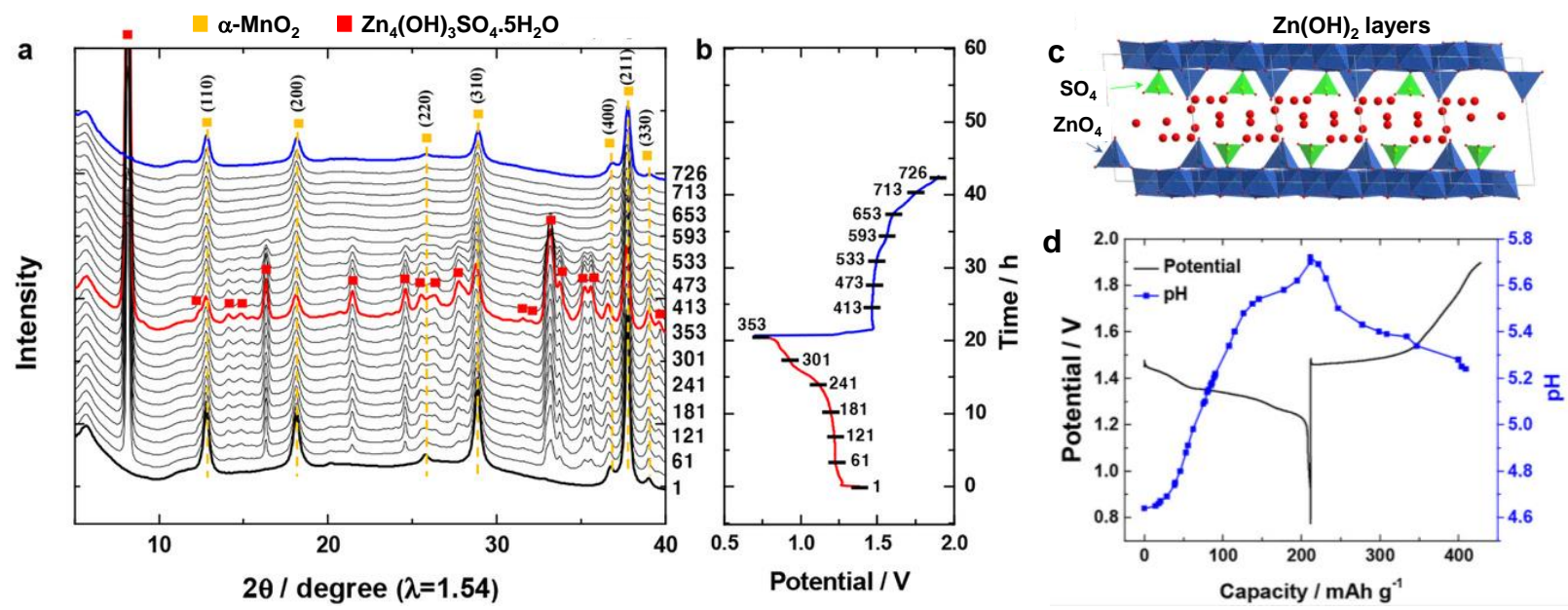

Figure 9: a) In situ XRD patterns recorded during $\mathrm{Zn}^{2+}$ insertion-de-insertion into/from $\alpha-\mathrm{MnO}_{2}$ in a zincbased aqueous rechargeable cell with $1 \mathrm{M} \mathrm{ZnSO}_{4}$ aqueous electrolyte at a rate of $\mathrm{C} / 20$, b) the corresponding discharge-charge curve, c) Crystal structure of $\mathrm{Zn}_{4}(\mathrm{OH})_{6} \mathrm{SO}_{4} .5 \mathrm{H}_{2} \mathrm{O}$, and d) $\mathrm{pH}$ variations during the first discharge-charge process [70].

\subsubsection{V-based oxides}

V-based materials (i.e. $\mathrm{V}^{4+} \mathrm{O}_{2}, \mathrm{~V}^{4+} \mathrm{S}_{2}, \mathrm{~V}^{4+, 5+}{ }_{3} \mathrm{O}_{7} \cdot \mathrm{H}_{2} \mathrm{O}, \mathrm{H}_{2} \mathrm{~V}^{4+, 5+}{ }_{3} \mathrm{O}_{8}$ or $\mathrm{Zn}_{0.25} \mathrm{~V}^{4+, 5}{ }_{2} \mathrm{O}_{5} \cdot \mathrm{nH}_{2} \mathrm{O}$ ) have also attracted attention for ZIBs due to the large panel of polymorphs that can be stabilized and to the different redox couples that can be involved, as vanadium is stable in different oxidation states $\mathrm{V}^{2+}, \mathrm{V}^{3+}, \mathrm{V}^{4+}$ and $\mathrm{V}^{5+}$. $\mathrm{Up}$ to now, the most promising results have been reported for $\mathrm{V}_{2} \mathrm{O}_{5} \cdot \mathrm{nH}_{2} \mathrm{O}$ and $\mathrm{Zn}_{0.25} \mathrm{~V}_{2} \mathrm{O}_{5} \cdot n \mathrm{nH}_{2} \mathrm{O}$, the later exhibiting $220 \mathrm{mAh} / \mathrm{g}$ at a $15 \mathrm{C}$ rate, and a capacity retention $>80 \%$ after 1,000 cycles [71]. These two compounds are very similar and their crystal structure consists of vanadium pentoxide bilayers and water molecules in between, with also zinc ions in the case of $\mathrm{Zn}_{0.25} \mathrm{~V}_{2} \mathrm{O}_{5} \cdot \mathrm{nH}_{2} \mathrm{O}$. (Fig. 10). The reaction mechanisms in ZIB are very similar to those already described for $\alpha-\mathrm{MnO}_{2}: \mathrm{Zn}^{2+}$ insertion as the main reaction and $\mathrm{H}^{+}$insertion as well as formation of $\mathrm{Zn}_{4} \mathrm{SO}_{4}(\mathrm{OH})_{6} \cdot 4 \mathrm{H}_{2} \mathrm{O}$ as parasitic process. Co-insertion of $\mathrm{Zn}^{2+}$ and $\mathrm{H}_{2} \mathrm{O}$ has been proposed for $\mathrm{V}_{2} \mathrm{O}_{5} \cdot \mathrm{nH}_{2} \mathrm{O}$ [72] and $\mathrm{Zn}_{0.25} \mathrm{~V}_{2} \mathrm{O}_{5} \cdot \mathrm{nH}_{2} \mathrm{O}$ [71] in which $\mathrm{H}_{2} \mathrm{O}$ molecules and/or $\mathrm{ZnO}_{6}$ octahedra would act as pillars and allow reversible expansions and shrinkages of the interlayer spacing to enable reversible $\mathrm{Zn}^{2+}$ intercalation and deintercalation. Likewise, the co-intercalation of water molecules would allow to screen the charges of $\mathrm{Zn}^{2+}$ ions and thus enhance the rate capability and capacity. The role of structural water was evidenced by solid state magic-angle-spinning (MAS) ${ }^{1} \mathrm{H}$ NMR [72], water acting as a "lubricant" to promote fast $\mathrm{Zn}^{2+}$ transportation (Fig. 10). 

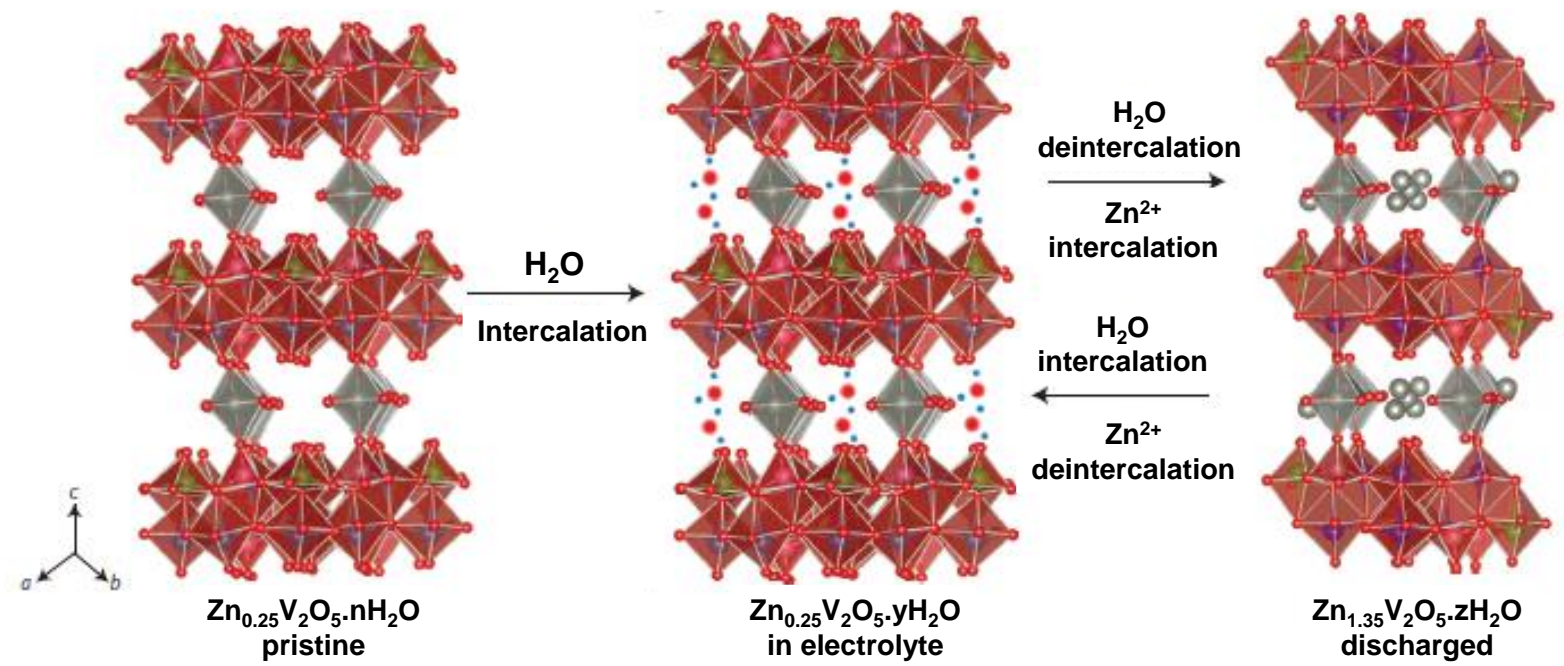

Figure 10: Scheme showing reversible water intercalation into $\mathrm{Zn}_{0.25} \mathrm{~V}_{2} \mathrm{O}_{5} \cdot \mathrm{nH}_{2} \mathrm{O}$ immersed in an aqueous electrolyte: water intercalation would "induce" further $\mathrm{Zn}^{2+}$ intercalation concomitant to partial $\mathrm{H}_{2} \mathrm{O}$ deintercalation. The red and blue spheres represent $\mathrm{O}$ and $\mathrm{H}$ respectively; the $\mathrm{H}_{2} \mathrm{O}$ molecules interact with the oxygen layers through hydrogen bonding. Here $y>z>n$, those being the fractions of intercalated $\mathrm{H}_{2} \mathrm{O}$ molecules during cell discharge [71].

\subsubsection{Prussian blue and its analogues}

Prussian blue (PB) and Prussian blue analogues (PBAs) have also received great attention with redox activity being mostly associated with $\mathrm{Zn}^{2+}$ ion insertion. For copper hexacyanoferrate $\left(\mathrm{C}_{6} \mathrm{Cu}_{4} \mathrm{FeN} \mathrm{N}_{6}\right)$ results of XPS analysis suggest that $\mathrm{Zn}^{2+}$ is inserted into the crystal structure and two low spin Fe ${ }^{\mathrm{III}}$ are converted simultaneously into low-spin Fe ${ }^{\mathrm{II}}$. The voltage of this battery system is as high as $1.73 \mathrm{~V}$ [73]. Despite their capacity not being very high (in most cases less than $70 \mathrm{mAh} / \mathrm{g}$ ) these compounds seem to exhibit good cycling stability and power performance.

\section{Challenges and Perspectives for Aqueous Electrolyte Batteries}

Independent from whether the energy storage option is based on the di- or univalent systems, the use of an aqueous electrolyte results in some issues when compared to the LiB technology. The most relevant challenges to overcome are discussed below and schematically depicted in Fig. 11. 


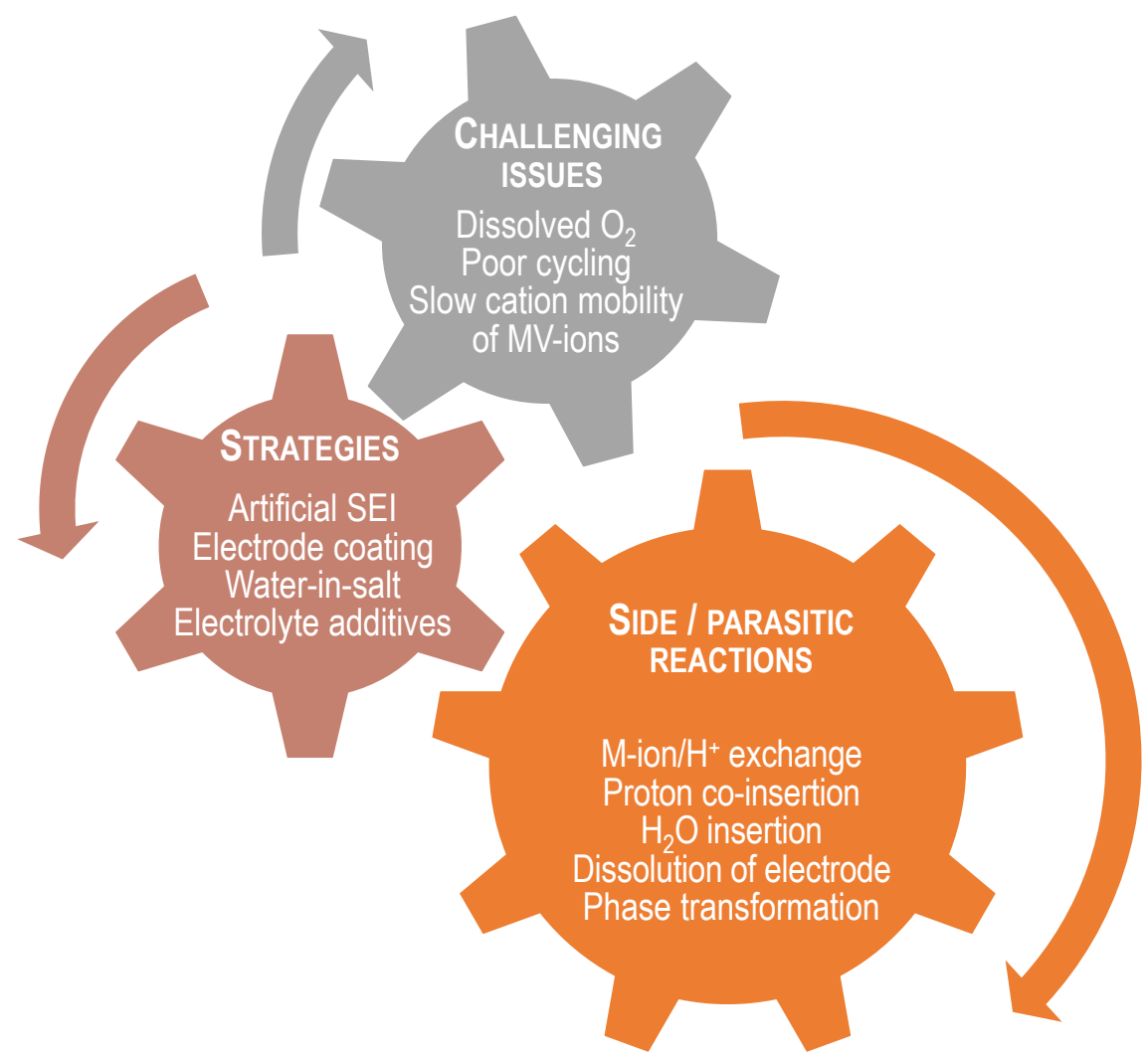

Figure 11. Main challenging issues of aqueous electrolyte batteries

\subsection{Narrow Thermodynamic Voltage Window}

As discussed above, typical aqueous $\mathrm{Li}(\mathrm{Na})$-ion batteries are limited to low voltage $(<1.5 \mathrm{~V})$ and low energy density $(<70 \mathrm{Wh} / \mathrm{kg}$ ), often exhibiting limited coulombic efficiency especially at low cycling rates. This is attributed to the existence of parasitic reactions, mostly related to water decomposition at very high/very low potentials.

The limitations in terms of electrochemical potential window are currently being challenged through: (i) the use of highly concentrated electrolytes ("water in salt concept") [74] and (ii) electrolyte additives. Moving to saturated aqueous electrolytes $\left(12 \mathrm{M}\right.$ for $\mathrm{Li}_{2} \mathrm{NO}_{3}$ and $2.9 \mathrm{M}$ for $\mathrm{Li}_{2} \mathrm{SO}_{4}$ ) was shown to enhance the coulombic efficiency of $\mathrm{LiFePO}_{4}$ in ARLBs, to achieve $>80 \%$ capacity retention after 500 cycles at a $1.1 \mathrm{C}$ rate in a potential window of $0.8 \mathrm{~V}$ [74] opening new research avenues to explore. Postmortem TEM analyses revealed no structural change in the bulk of the active material, but showed the formation of an amorphous surface layer which was found to be rather thick (up to $6 \mathrm{~nm}$ ) for the most stable cells.

Since polarity of water molecules enables water to dissolve ionically bonded substances (i.e. salts), its positive part (the hydrogen atoms) attracting the anions and its negative part (the oxygen atom) interacting with the cations, a solvation (or in the case of water hydration) shell surrounds the both anions and cations $\left(\mathrm{Li}^{+}, \mathrm{Na}^{+}\right.$etc.), which has a significant difference when compared to organic electrolytes in which anions are almost unsolvated and hence cation transference numbers are very low. The thickness of the sheath can 
vary depending on the charge of the ion, its distribution and spatial dimensions. In the presence of a water in salt complex, (Fig. 12), the high salt concentration leads the anions (i.e. TFSI') to enter in the (i.e. $\mathrm{Li}^{+}$) solvation sheath to compensate locally for the electrostatic field as there are not enough water molecules to do so. The close interaction between $\mathrm{Li}^{+}$and TFSI ${ }^{-}$has been confirmed by Raman and ${ }^{17} \mathrm{O}{ }^{\mathrm{NMR}}$ spectroscopy. The benefits of using these electrolytes are two-fold: (i) no interaction of the water molecules with the electrode-electrolyte interface since they are too scarce, and (ii) interaction of the anions TFSI ${ }^{-}$with this interface leading to the formation of an SEI layer. According to thermal analyses the water-in-salt electrolytes are liquids at $25^{\circ} \mathrm{C}$ and can be cooled down to $-90^{\circ} \mathrm{C}$ with a negligible crystallization of the salt, and its conductivity remaining $\sim 10 \mathrm{mS} / \mathrm{cm}$, comparable to that of a typical organic electrolytes $(9.0$ $\mathrm{mS} / \mathrm{cm})$.

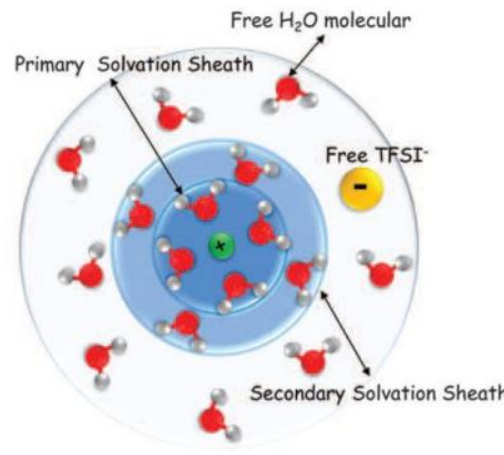

$\left\{\left[\mathrm{Li}\left(\mathrm{H}_{2} \mathrm{O}\right)_{4}\right]\left(\mathrm{H}_{2} \mathrm{O}\right)_{4}\right\}+\mathrm{nH}_{2} \mathrm{O} \mathrm{n} \geq 1$

Salt-in-Water

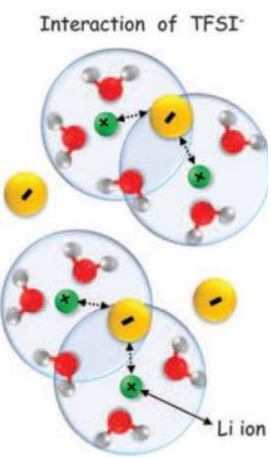

$\operatorname{Li}\left(\mathrm{H}_{2} \mathrm{O}\right)_{2.5}$-TFSI

Water-in-Salt

Figure 12: Illustration of the changes in the $\mathrm{Li}^{+}$primary solvation sheath in diluted (left) and water-in-salt (right) electrolytes. 4 or 2.5 water molecules are present in the primary solvation sheath $\mathrm{f}^{+}$, moving from the diluted (salt-in-water) to the highly concentrated (water-in-salt) electrolytes respectively [75].

More insights into the mechanisms involved were recently obtained combining especially FTIR, ${ }^{1} \mathrm{H},{ }^{7} \mathrm{Li}$ and ${ }^{19} \mathrm{~F}$ NMR and electrochemical experiments [76]. Indeed, these results clearly evidence that water reduction to form $\mathrm{H}_{2}$ does indeed take place in these systems (Fig. 13), with the formation of a fluorine-rich SEI as a result of a chemical reaction due to the hydroxide ions formed during reduction of water and reacting with TFSI anions.

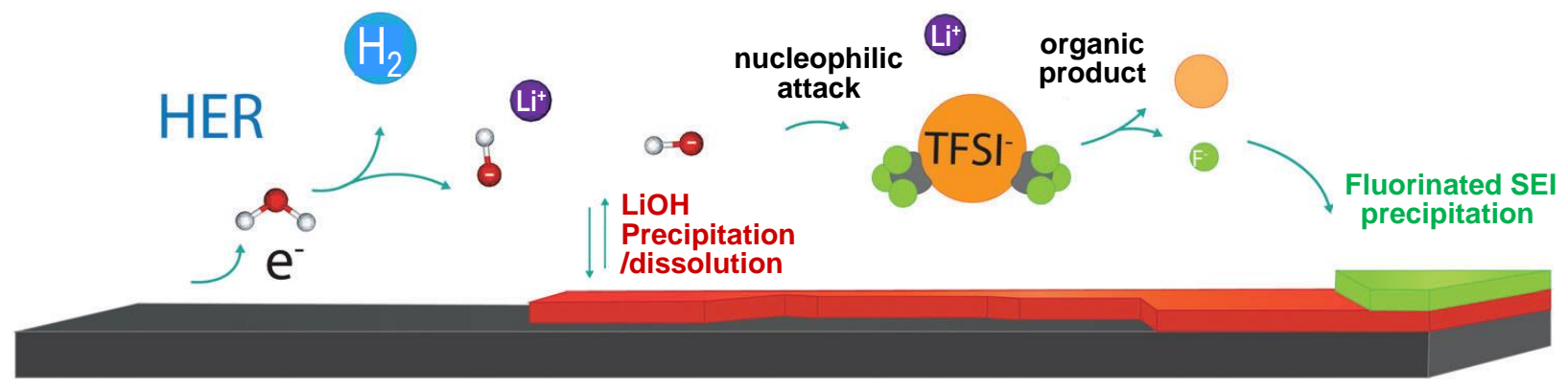


Figure 13: Scheme representing the formation of a stabilizing Fluorine-rich SEI at the surface of the negative electrode [76]

Aqueous electrolytes constituted by a mixture of lithium salts with different anions termed "hydrate melts" (e.g. $\mathrm{Li}(\mathrm{TFSI})_{0.7}(\mathrm{BETI})_{0.3} \cdot 2 \mathrm{H}_{2} \mathrm{O}$ ) have also been reported to exhibit an extremely large potential window up to $3 \mathrm{~V}$ (Fig. 14) enabling the assembly of $2.4 \mathrm{~V} \mathrm{LiCoO}_{2} / \mathrm{Li}_{4} \mathrm{Ti}_{5} \mathrm{O}_{12}$ and $3.1 \mathrm{~V} \mathrm{LiNi}{ }_{0.5} \mathrm{Mn}_{1.5} \mathrm{O}_{4} / \mathrm{Li}_{4} \mathrm{Ti}_{5} \mathrm{O}_{12}$ cells [77]. The use of two salts with very similar properties allow to overpass the solubility of LiTFSI in water and to decrease further the concentration in water. As an example, the hydrate melt made of the two organic Li salts $(0.7 \mathrm{LiTFSI}+0.3 \mathrm{LiBETI})$ shows a minimized content in water $(6.30 \mathrm{~mol} / \mathrm{kg}$ only in a high concentration in salts $27.8 \mathrm{~mol} / \mathrm{kg}$ ). Playing with the chemistry of these melts it should be possible to tailor the composition of the SEI formed at the surface of the negative electrode and thus to stabilize - as proposed by Grimaud et al. [76] - these aqueous systems versus water reduction.

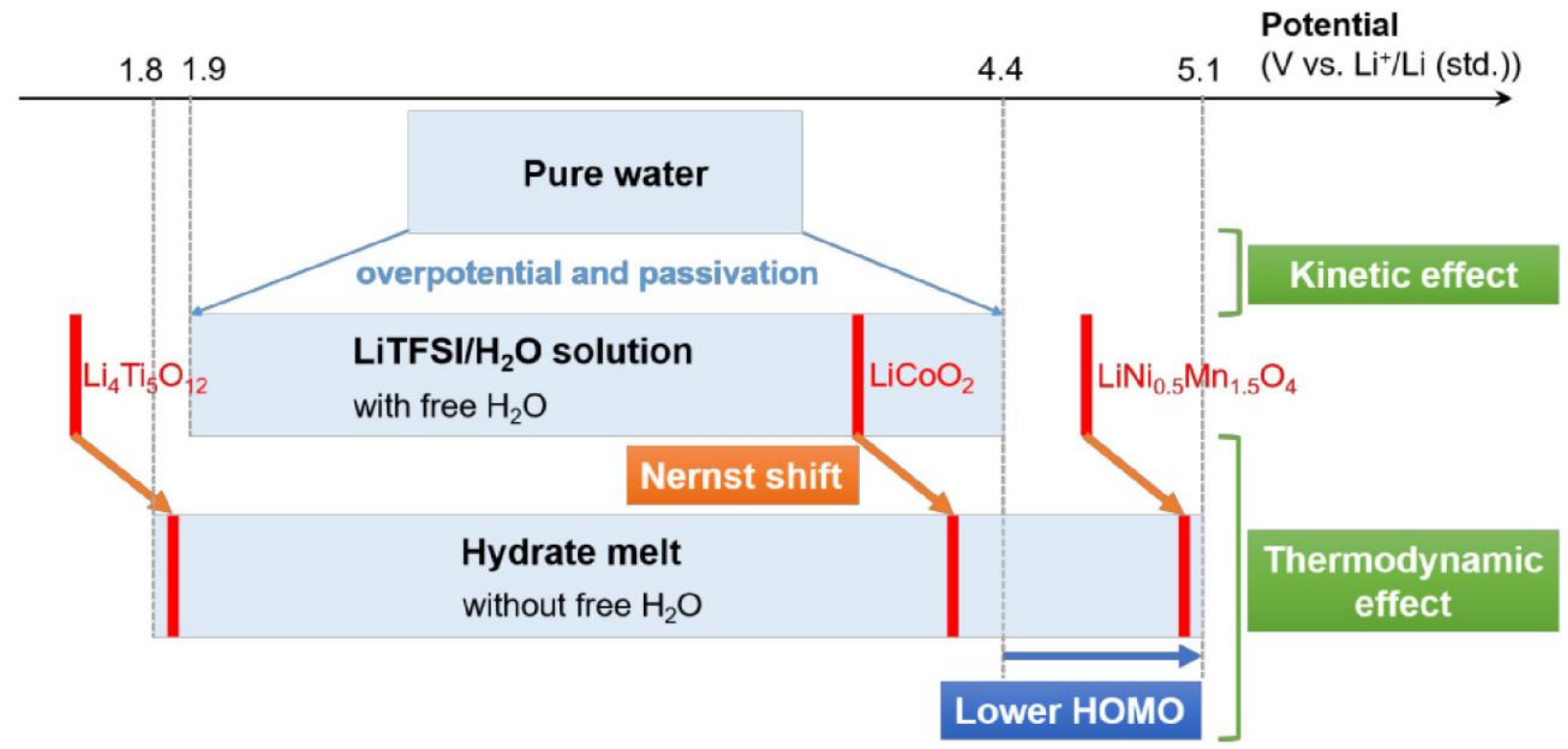

Figure 14: Electrochemical stability windows for pure water compared to concentrated LiTFSI in water. Potential vs. $\mathrm{pH}$ stability diagram of water at $25^{\circ} \mathrm{C}$. Below the "hydrate melts". The operation potential of diverse conventional electrode materials for organic electrolyte $\mathrm{Li}$-ion batteries are depicted in red [77].

It is also interesting to mention that combining the strategies mentioned above the layered oxide $\mathrm{LiCoO}_{2}$ was successfully stabilized at a high cut-off voltage enabling the reversible deintercalation and reintercalation of $0.7 \mathrm{Li}^{+}$and thus to $170 \mathrm{mAh} / \mathrm{g}$ [74] using $\mathrm{Mo}_{6} \mathrm{~S}_{8}$ at the negative electrode. The cells were shown to deliver a high energy density of $120 \mathrm{Wh} / \mathrm{kg}$ (per total weight of electrodes) during 1000 cycles performed at $2.5 \mathrm{C}$ and the capacity decay was limited to $0.013 \%$ per cycle. The key issue here appears to be the use of TMSB (tris(trimethylsilyl) borate) as an additive in the water-in-salt electrolyte (21M LiTFSI $+0.1 \mathrm{wt} \%$ TMSB), as XPS and TEM supported by first principles calculations demonstrated that TMSB is electrochemically oxidized forming a dense SEI on the surface of $\mathrm{LiCoO}_{2}$. This SEI contains mainly $\mathrm{Si}(\mathrm{OH})_{4}$ and $\mathrm{B}(\mathrm{OH})_{3}$ and helps preventing Co dissolution and other parasitic reactions at the electrode-electrolyte interface. 
The "water-in-salt" concept was also recently spread into the field of ZIBs, with the use of high concentrated salt consisting of $1 \mathrm{M} \mathrm{Zn(TFSI})_{2}+20 \mathrm{M}$ LiTFSI [78]. When high LiTFSI salt concentrations are used $(\geq 20$ $\mathrm{M}), \mathrm{Zn}^{2+}$ is preferentially surrounded by $\mathrm{TFSI}^{-}$anions according to molecular dynamics and spectroscopic studies. Stable (Zn-TFSI) ${ }^{+}$species are formed, suppressing $\mathrm{ZnO}$ formation driven by the strong interaction between $\mathrm{Zn}^{2+}$ and $\mathrm{H}_{2} \mathrm{O}$ enabling long cycling stability over 4000 cycles without dendrite formation. Yet, in light of the results reported for Li-ion systems [76], it is likely that water reduction is not suppressed in this system either, globally challenging viability of the approach.

\subsection{Side Reactions Critical to Control}

The presence of $\mathrm{O}_{2}$ in the electrolyte comes either from the hydrolysis of $\mathrm{H}_{2} \mathrm{O}$, or arises from the fact that metal-ion batteries operate in air. This presence is highly detrimental to the cycling performance of the cells, since dissolved oxygen may chemically oxidize the electrode materials regardless of the $\mathrm{pH}$ of the electrolyte. For instance, $\mathrm{LiFePO}_{4}$ when operating in water reacts with $\mathrm{O}_{2}$ to form $\mathrm{Fe}_{2} \mathrm{O}_{3}$ and $\mathrm{Li}_{3} \mathrm{PO}_{4}$, leading to a fast capacity loss. To overcome this issue, the usual recipe is to coat the electrode material either with a thin layer of carbon or with a polymer, as well as bubbling $\mathrm{N}_{2}$ and Ar gases into the electrolyte prior to work.

Dissolution of active material has been shown to be a major problem causing capacity fading. This is related to the composition of the electrolyte (with $\mathrm{pH}$ playing a very relevant role) and also to the composition of active material, with manganese being more prone to dissolution. Indeed, disproportionation of $\mathrm{Mn}^{3+}$ in manganese containing oxides to yield $\mathrm{Mn}^{4+}$ and $\mathrm{Mn}^{2+}$ which would dissolve in the electrolyte has been observed both in ARLBs and ZIBs. For the latter, results of elemental analysis indicate that the dissolution of $\mathrm{Mn}^{2+}$ ions stabilizes after the initial 10 cycles after having reached a certain concentration threshold. Therefore, pre-addition of a certain amount of $\mathrm{Mn}^{2+}$ ions to the electrolyte seems to be a means to overcome the issue.

The critical role of the current collectors: Auto dissociation products of water into $\mathrm{OH}^{-}$and $\mathrm{H}_{3} \mathrm{O}^{+}$are highly reactive and can readily react with current collectors leading to corrosion. Likewise, electrolyte salts also play a crucial role. For instance, even though the conductivity of sulphate salts is lower than that of chlorides, zinc-ion battery studies in the literature mostly focus on $\mathrm{ZnSO}_{4}$ as the electrolyte salt since it is much less corrosive than chloride to stainless steel. As a whole, the choice of the current collector in the field of aqueous electrolytes is very important since all the cell components need to be both chemically and electrochemically stable. In the field of metal-ion battery systems, the current collectors are usually made of stainless steel, graphite, titanium mesh or nickel meshes, which have different resistances to corrosion, the $\mathrm{pH}$ of the electrolyte being the main factor determining the final choice. While stainless steel and nickel mesh cannot be used in acidic media, since they can react with the high concentration of $\mathrm{H}^{+}$and have low corrosion potential at the basic media, usually, titanium meshes are suggested with high cycling stability. All these current collectors are expensive and heavier than aluminium (used in conventional non-aqueous Lithium-ion batteries), which is unfortunately prone to corrosion in aqueous media. Nevertheless, recent promising results have been obtained for ARLBs using a surface modified aluminium collector [79]. The formation of a chromium oxy-hydroxide monolayer as a coating was shown first to prevent the irreversible formation of $\mathrm{Al}(\mathrm{OH})_{3}$ at the interface between the aluminium foil and the electrolyte, and then to block the adsorption sites and the formation of the intermediate species at the origin of oxygen evolution [80, 81]. [81]. Replacing the current collector made of stainless steel by one made of aluminium modified by a coating allows pushing up the oxygen evolution peak of $2.7 \mathrm{~V}$. As discussed in detail hereafter for hydrogen 
evolution, the oxygen evolution is also strongly controlled by the metal-oxygen bond energies, typically dependent on the nature of the metal and of the surface groups

The metal- hydrogen $(\mathrm{M}-\mathrm{H})$ bond energies are typically used to understand and rationalize the hydrogen evolution at the surface of the current collector and can be shown with a volcano curve depicted in Fig. 15 $[11,82]$. Hydrogen evolution rate is measured by the exchange current density and this volcano-shape is formed by measuring those metals' $\mathrm{H}_{2}$ evolution currents in comparison with their bonding strengths. While $\mathrm{H}_{2}$ evolution ability is enhanced by tightly $\mathrm{H}$-bonding on the metal surface on the left side of the volcano, the trend is opposite on the right side of the volcano. The decreased tendency of the $\mathrm{H}_{2}$ evolution by increasing $\mathrm{M}-\mathrm{H}$ bond energy can be explained by the decrease in the available sites on the surface for the $\mathrm{H}+\mathrm{H}$ recombination reaction. For instance, the ability of $\mathrm{Pt}$ metal to catalyse the hydrogen evolution reaction is high and well known, thus, resulting it as a perfect candidate for electrocatalytic reactions in fuel cells. On the other hand, in battery applications, $\mathrm{H}_{2}$ evolution should be minimized and thus, $\mathrm{Zn}$ or $\mathrm{Pb}$ are metals of choice in this domain. Ti is also expected to show sufficient delay in $\mathrm{H}_{2}$ evolution, however it is generally avoided due to its high cost.

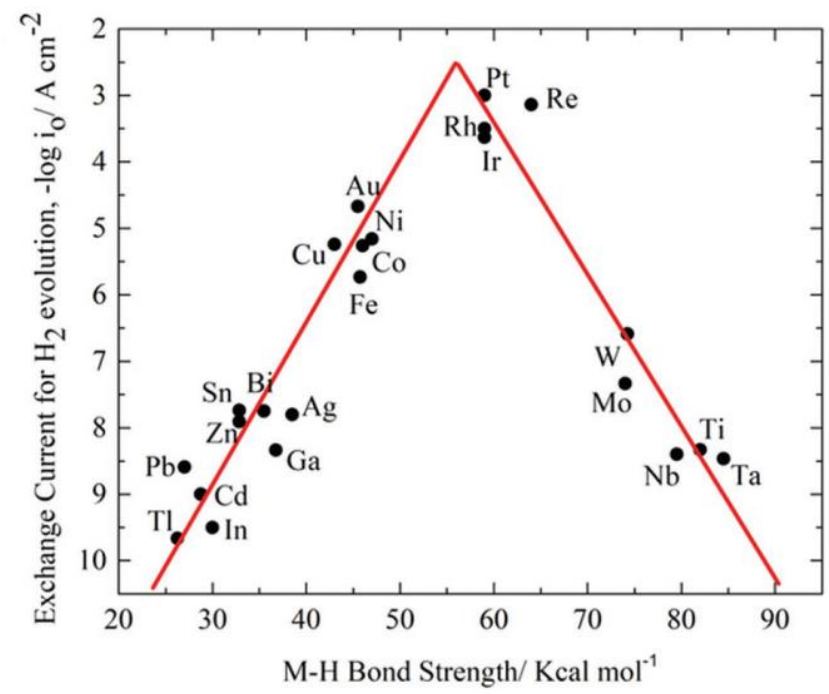

Figure 15: Exchange currents for electrolytic $\mathrm{H}_{2}$ evolution versus metal-hydrogen bond strength for different elements [11]

\subsection{Future perspectives}

Aqueous rechargeable metal-ion batteries are promising alternatives for large-scale stationary energy storage systems because:

- They are safer due to the use of an aqueous electrolyte instead of flammable organic electrolytes.

- Their manufacturing does not require to be performed in rigorous water-free conditions, and is thus a lower cost fabrication process.

- The electrolytes and the separators are cheaper, whereas the salts and solvent are benign for the environment and nontoxic.

- The ionic conductivity of the aqueous electrolytes is two orders of magnitude higher than that of an organic-based electrolyte. This enables successful prospects of developing batteries with thick electrodes (high energy) exhibiting at the same time high power capability. 
The nature of water as a solvent and the strong influence of aqueous electrolytes in metal ion intercalation processes are indeed distinct from these existing in non-aqueous electrolytes. In addition to the already discussed configurations that are very promising to meet the expectations from the grid applications in terms of high power, safety, low cost and cyclability, further identification and optimization of positive and negative electrode couples for aqueous rechargeable batteries are imperative if higher energy densities $(>200 \mathrm{Wh} / \mathrm{kg})$ are to be attained.

Prospective research is also in course to tentatively use protected lithium metal at the negative electrode. Viable protected lithium metal anodes were first developed by the PolyPlus Battery Company using waterstable high $\mathrm{Li}^{+}$conductivity solid electrolytes to chemically isolate a lithium core from the external environment [83]. The compound most commonly used is $\mathrm{Li}_{1.3} \mathrm{Al}_{0.3} \mathrm{Ti}_{1.7}\left(\mathrm{PO}_{4}\right)_{3}$ (LATP) produced in Japan by Ohara Corporation and in the US by Corning which exhibits an ionic conductivity of about $10^{-4} \mathrm{~S} / \mathrm{cm}$ at room temperature. LATP is not stable in contact with lithium as titanium can be reduced and thus there is need to incorporate an additional interlayer which can be solid (e.g. $\left.\mathrm{Li}_{3} \mathrm{~N}\right)$, polymeric, a ionic liquid or even a non-aqueous liquid electrolyte. This strategy would prevent the contact of the Li metal anode with the electrolyte and makes it stable versus any reactivity. Yet, bottlenecks related to the stability of the coatings (both mechanical and chemical) still remain to be solved before this approach can be considered viable.

Researchers working in new aqueous chemistries do usually take Li-ion figures of merit for performance comparison and thus the values obtained always fall short. Moreover, despite the ability to use thicker electrodes in aqueous technologies the number of cells required to build modules and packs with a certain energy density will most likely be somewhat larger and increase the complexity of the system. Under this scenario, Li-ion battery cost reduction (current values close to $200 \$ / \mathrm{kWh}$ at cell level and $450 \$ / \mathrm{kWh}$ at pack level) due to mass production is challenging any advance in alternative technologies. In line with these arguments, some aqueous battery technologies that made their way to development (e.g. Aquion company) were found not to be competitive enough.

Unless further research efforts bring about breakthroughs in performance, aqueous M-ion technologies may have a market only for niche applications where avoidance of organic solvents for safety reasons is a must. Along that line, the use of $\mathrm{Na}$ instead of Li coupled to electrode materials based on unexpensive abundant metals (Ti or Mn for instance) would add the sustainability perspective. Moreover, given the good power rate of the current aqueous M-ion technologies, they may be competitive versus asymmetric supercapacitors in terms of performances, especially if similar cost can be reached.

The replacement of inorganic transition metal based electrode materials by organic ones is actually another interesting alternative which is starting to be explored. Despite their low density, they would bring about improvement in terms of lower cost and environmentally friendly systems. As an example, $1.2 \mathrm{~V}$ full cells made of $100 \mathrm{~nm}$ thick electrodes of poly(2,2,6,6-tetramethylpiperidinyloy-4-yl acrylamide) (PTAm) and poly(N-4,4'-bipyridinium-N-decamethylene dibromide) (PV10) with $0.1 \mathrm{M} \mathrm{NaBF}_{4}$ as electrolyte [84] demonstrated 2000 cycles at $60 \mathrm{C}$ with a capacity loading of $0.78 \mu \mathrm{Ah} / \mathrm{cm}^{2}$. The energy density delivered by these systems based on radical polymers is very limited and only sufficient to supply devices such as IC tags and smart cards. More recently, the formation of hybrid electrodes combining the radical polymer PTAm with single-walled carbon nanotubes allowed reaching very good performance in half cells for submillimeter thick electrodes $\left(3 \mathrm{mAh} / \mathrm{cm}^{2}\right)$, paving thus the way for the development of higher energy density systems [85]. Another attractive strategy recently proposed deals with the use of small organic 
molecules instead of radical polymers. [86] However, concerns about the stability upon long range cycling, storage in the charge state etc. remain for all these organic electrode systems, as is the case for the related concepts using organic electrolytes.

Overall, the aqueous battery field is unquestionably growing and improved performance being achieved. Yet, in some cases it is complex to grasp the practical relevance in the reported findings. Indeed, information about active material loading, electrode thickness, negative/positive electrode balance, amount of electrolyte used as well as type/weight of the current collectors are often lacking. Realistic estimates of the practical energy densities achievable with these technologies using open source models are mandatory to assess whether these technologies can compete with already available batteries at the marketplace [87, 88]. There is thus still a long way to go in the field. Investigations for the production and evaluation of thick composite electrodes are required including current collectors, considering for instance graphite paper sheets, binders, conducting additives, and the electrolyte, with the goals to adjust the power-energy ratio for stationary applications and to reduce the overall cost of the battery.

\section{Acknowledgements}

LC and MRP are grateful to ALISTORE-ERI members for fruitful interaction and discussions. LC acknowledges her colleague Liliane Guerlou-Demourgues for fruitful discussions, and Région Nouvelle Aquitaine, the French network (RS2E) on the electrochemical energy storage as well as the French National Research Agency (STORE-EX Labex Project ANR-10-LABX-76-01) for their support to her research on electrode materials for batteries. MRP acknowledges funding from Spanish Ministry of Science, Innovation and Universities through grant MAT2017-86616-R and support from the "Severo Ochoa" Programme for Centres of Excellence in R\&D (SEV- 2015-0496). RDC is thankful for the funding from TÜBİTAK (The Scientific and Technological Research Council of Turkey) 1001 Program (Contract No: 114Z920) and International Bilateral Project between Turkey and France (Contracts No: 113M105 and 214M272).

\section{References}

[1] D.P. Dubal, O. Ayyad, V. Ruiz, P. Gomez-Romero, Hybrid energy storage: the merging of battery and supercapacitor chemistries, Chemical Society Reviews, 44 (2015) 1777-1790.

[2] P. Simon, Y. Gogotsi, B. Dunn, Where Do Batteries End and Supercapacitors Begin?, Science, 343 (2014) 1210-1211.

[3] J.H. Huang, Z.W. Guo, Y.Y. Ma, D. Bin, Y.G. Wang, Y.Y. Xia, Recent Progress of Rechargeable Batteries Using Mild Aqueous Electrolytes, Small Methods, 3 (2019).

[4] G.Z. Fang, J. Zhou, A.Q. Pan, S.Q. Liang, Recent Advances in Aqueous Zinc-lon Batteries, Acs Energy Letters, 3 (2018) 2480-2501.

[5] H. Kim, J. Hong, K.Y. Park, H. Kim, S.W. Kim, K. Kang, Aqueous Rechargeable Li and Na lon Batteries, Chemical Reviews, 114 (2014) 11788-11827.

[6] F. Beck, P. Ruetschi, Rechargeable batteries with aqueous electrolytes, Electrochimica Acta, 45 (2000) 2467-2482.

[7] W. Manalastas, S. Kumar, V. Verma, L.P. Zhang, D. Yuan, M. Srinivasan, Water in Rechargeable Multivalent-Ion Batteries: An Electrochemical Pandora's Box, Chemsuschem, 12 (2019) 379-396. 
[8] J. Liu, C. Xu, Z. Chen, S. Ni, Z.X. Shen, Progress in aqueous rechargeable batteries, Green Energy and Environment, 3 (2018) 20-41.

[9] D. Bin, Y.P. Wen, Y.G. Wang, Y.Y. Xia, The development in aqueous lithium-ion batteries, Journal of Energy Chemistry, 27 (2018) 1521-1535.

[10] S. Boyd, V. Augustyn, Transition metal oxides for aqueous sodium-ion electrochemical energy storage, Inorganic Chemistry Frontiers, 5 (2018) 999-1015.

[11] V. Verma, S. Kumar, W. Manalastas, R. Satish, M. Srinivasan, Progress in Rechargeable Aqueous Zincand Aluminum-Ion Battery Electrodes: Challenges and Outlook, Advanced Sustainable Systems, 3 (2019).

[12] M. Okoshi, Y. Yamada, S. Komaba, A. Yamada, H. Nakai, Theoretical Analysis of Interactions between Potassium Ions and Organic Electrolyte Solvents: A Comparison with Lithium, Sodium, and Magnesium Ions, Journal of the Electrochemical Society, 164 (2017) A54-A60.

[13] J.B. Goodenough, K.S. Park, The Li-Ion Rechargeable Battery: A Perspective, Journal of the American Chemical Society, 135 (2013) 1167-1176.

[14] D. Linden and T.B. Reddy, Handbook of Batteries, Mc Graw-Hill, New York, (2002).

[15] K. Xu, Nonaqueous liquid electrolytes for lithium-based rechargeable batteries, Chemical Reviews, 104 (2004) 4303-4417.

[16] K. Xu, Electrolytes and Interphases in Li-Ion Batteries and Beyond, Chemical Reviews, 114 (2014) 11503-11618.

[17] O. Pecher, J. Carretero-Gonzalez, K.J. Griffith, C.P. Grey, Materials' Methods: NMR in Battery Research, Chemistry of Materials, 29 (2017) 213-242.

[18] F. Lin, Y.J. Liu, X.Q. Yu, L. Cheng, A. Singer, O.G. Shpyrko, H.L.L. Xing, N. Tamura, C.X. Tian, T.C. Weng, X.Q. Yang, Y.S. Meng, D. Nordlund, W.L. Yang, M.M. Doeff, Synchrotron X-ray Analytical Techniques for Studying Materials Electrochemistry in Rechargeable Batteries, Chemical Reviews, 117 (2017) 1312313186.

[19] M.D. Levi, N. Levy, S. Sigalov, G. Salitra, D. Aurbach, J. Maier, Electrochemical Quartz Crystal Microbalance (EQCM) Studies of lons and Solvents Insertion into Highly Porous Activated Carbons, Journal of the American Chemical Society, 132 (2010) 13220-13222.

[20] N. Shpigel, M.D. Levi, S. Sigalov, L. Daikhin, D. Aurbach, In Situ Real-Time Mechanical and Morphological Characterization of Electrodes for Electrochemical Energy Storage and Conversion by Electrochemical Quartz Crystal Microbalance with Dissipation Monitoring, Accounts of Chemical Research, 51 (2018) 69-79.

[21] W. Li, J.R. Dahn, D.S. Wainwright, RECHARGEABLE LITHIUM BATTERIES WITH AQUEOUSELECTROLYTES, Science, 264 (1994) 1115-1118.

[22] H. Manjunatha, G.S. Suresh, T.V. Venkatesha, Electrode materials for aqueous rechargeable lithium batteries, Journal of Solid State Electrochemistry, 15 (2011) 431-445.

[23] Y.G. Wang, J. Yi, Y.Y. Xia, Recent Progress in Aqueous Lithium-Ion Batteries, Advanced Energy Materials, 2 (2012) 830-840.

[24] N. Cvjeticanin, I. Stojkovic, M. Mitric, S. Mentus, Cyclic voltammetry of LiCr0.15Mn1.8504 in an aqueous LiNO3 solution, Journal of Power Sources, 174 (2007) 1117-1120.

[25] R. Benedek, M.M. Thackeray, A. van de Walle, Free energy for protonation reaction in lithium-ion battery cathode materials, Chemistry of Materials, 20 (2008) 5485-5490.

[26] P. He, J.L. Liu, W.J. Cui, J.Y. Luo, Y.Y. Xia, Investigation on capacity fading of LiFePO4 in aqueous electrolyte, Electrochimica Acta, 56 (2011) 2351-2357.

[27] J.Y. Luo, W.J. Cui, P. He, Y.Y. Xia, Raising the cycling stability of aqueous lithium-ion batteries by eliminating oxygen in the electrolyte, Nature Chemistry, 2 (2010) 760-765.

[28] F. Wang, Y. Liu, C.Y. Liu, Hydrothermal synthesis of carbon/vanadium dioxide core-shell microspheres with good cycling performance in both organic and aqueous electrolytes, Electrochimica Acta, 55 (2010) 2662-2666. 
[29] W. Tang, L.L. Liu, Y.S. Zhu, H. Sun, Y.P. Wu, K. Zhu, An aqueous rechargeable lithium battery of excellent rate capability based on a nanocomposite of $\mathrm{MoO} 3$ coated with PPy and LiMn2O4, Energy \& Environmental Science, 5 (2012) 6909-6913.

[30] H.Q. Li, T.Y. Zhai, P. He, Y.G. Wang, E. Hosono, H.S. Zhou, Single-crystal H2V3O8 nanowires: a competitive anode with large capacity for aqueous lithium-ion batteries, Journal of Materials Chemistry, 21 (2011) 1780-1787.

[31] C. Wessells, R. Ruffo, R.A. Huggins, Y. Cui, Investigations of the Electrochemical Stability of Aqueous Electrolytes for Lithium Battery Applications, Electrochemical and Solid State Letters, 13 (2010) A59-A61.

[32] Y.G. Wang, Y.Y. Xia, Hybrid aqueous energy storage cells using activated carbon and lithiumintercalated compounds I. The C/LiMn2O4 system, Journal of the Electrochemical Society, 153 (2006) A450-A454.

[33] O. Hanna, S. Luski, T. Brousse, D. Aurbach, Aqueous energy-storage cells based on activated carbon and LiMn2O4 electrodes, Journal of Power Sources, 354 (2017) 148-156.

[34] R. Demir-Cakan, M. Morcrette, J.B. Leriche, J.M. Tarascon, An aqueous electrolyte rechargeable Liion/polysulfide battery, Journal of Materials Chemistry A, 2 (2014) 9025-9029.

[35] S. Sevinc, B. Tekin, A. Ata, M. Morcrette, H. Perrot, O. Sel, R. Demir-Cakan, In-situ tracking of NaFePO4 formation in aqueous electrolytes and its electrochemical performances in Na-ion/polysulfide batteries, Journal of Power Sources, 412 (2019) 55-62.

[36] R. Demir-Cakan, M. Morcrette, J.M. Tarascon, Use of ion-selective polymer membranes for an aqueous electrolyte rechargeable Li-ion-polysulphide battery, Journal of Materials Chemistry A, 3 (2015) 2869-2875.

[37] F. Sauvage, E. Baudrin, J.M. Tarascon, Study of the potentiometric response towards sodium ions of $\mathrm{Na0.44-xMnO2}$ for the development of selective sodium ion sensors, Sensors and Actuators B-Chemical, 120 (2007) 638-644.

[38] J.F. Whitacre, A. Tevar, S. Sharma, Na4Mn9O18 as a positive electrode material for an aqueous electrolyte sodium-ion energy storage device, Electrochemistry Communications, 12 (2010) 463-466.

[39] Y.S. Wang, J. Liu, B.J. Lee, R.M. Qiao, Z.Z. Yang, S.Y. Xu, X.Q. Yu, L. Gu, Y.S. Hu, W.L. Yang, K. Kang, H. Li, X.Q. Yang, L.Q. Chen, X.J. Huang, Ti-substituted tunnel-type Na0.44MnO2 oxide as a negative electrode for aqueous sodium-ion batteries, Nature Communications, 6 (2015).

[40] B.H. Zhang, Y. Liu, X.W. Wu, Y.Q. Yang, Z. Chang, Z.B. Wen, Y.P. Wu, An aqueous rechargeable battery based on zinc anode and $\mathrm{Na0.95MnO2,} \mathrm{Chemical} \mathrm{Communications,} 50$ (2014) 1209-1211.

[41] K. Nakamoto, Y. Kano, A. Kitajou, S. Okada, Electrolyte dependence of the performance of a $\mathrm{Na} 2 \mathrm{FeP2O} / / \mathrm{NaTi2}(\mathrm{PO} 4)(3)$ rechargeable aqueous sodium-ion battery, Journal of Power Sources, 327 (2016) 327-332.

[42] Y.H. Jung, C.H. Lim, J.H. Kim, D.K. Kim, Na2FeP2O7 as a positive electrode material for rechargeable aqueous sodium-ion batteries, Rsc Advances, 4 (2014) 9799-9802.

[43] W.X. Song, X.B. Ji, Y.R. Zhu, H.J. Zhu, F.Q. Li, J. Chen, F. Lu, Y.P. Yao, C.E. Banks, Aqueous Sodium-Ion Battery using a Na3V2(PO4)(3) Electrode, Chemelectrochem, 1 (2014) 871-876.

[44] H. Qin, Z.P. Song, H. Zhan, Y.H. Zhou, Aqueous rechargeable alkali-ion batteries with polyimide anode, Journal of Power Sources, 249 (2014) 367-372.

[45] A.J. Fernandez-Ropero, D. Saurel, B. Acebedo, T. Rojo, M. Casas-Cabanas, Electrochemical characterization of NaFePO4 as positive electrode in aqueous sodium-ion batteries, Journal of Power Sources, 291 (2015) 40-45.

[46] X.Y. Wu, M.Y. Sun, Y.F. Shen, J.F. Qian, Y.L. Cao, X.P. Ai, H.X. Yang, Energetic Aqueous Rechargeable Sodium-Ion Battery Based on Na2CuFe(CN)(6)-NaTi2(PO4)(3) Intercalation Chemistry, Chemsuschem, 7 (2014) 407-411. 
[47] X.Y. Wu, M.Y. Sun, S.M. Guo, J.F. Qian, Y. Liu, Y.L. Cao, X.P. Ai, H.X. Yang, Vacancy-Free Prussian Blue Nanocrystals with High Capacity and Superior Cyclability for Aqueous Sodium-Ion Batteries, Chemnanomat, 1 (2015) 188-193.

[48] S. II Park, I. Gocheva, S. Okada, J. Yamaki, Electrochemical Properties of NaTi2(PO4)(3) Anode for Rechargeable Aqueous Sodium-Ion Batteries, Journal of the Electrochemical Society, 158 (2011) A1067A1070.

[49] Z. Li, D.B. Ravnsbaek, K. Xiang, Y.M. Chiang, Na3Ti2(PO4)(3) as a sodium-bearing anode for rechargeable aqueous sodium-ion batteries, Electrochemistry Communications, 44 (2014) 12-15.

[50] H.C. Gao, J.B. Goodenough, An Aqueous Symmetric Sodium-Ion Battery with NASICON-Structured $\mathrm{Na3MnTi(PO4)(3),} \mathrm{Angewandte} \mathrm{Chemie-International} \mathrm{Edition,} 55$ (2016) 12768-12772.

[51] T. Yamamoto, T. Shoji, RECHARGEABLE ZN/ZNSO4/MNO2-TYPE CELLS, Inorganica Chimica Acta, 117 (1986) L27-L28.

[52] C.J. Xu, B.H. Li, H.D. Du, F.Y. Kang, Energetic Zinc Ion Chemistry: The Rechargeable Zinc lon Battery, Angewandte Chemie-International Edition, 51 (2012) 933-935.

[53] A. Konarov, N. Voronina, J.H. Jo, Z. Bakenov, Y.K. Sun, S.T. Myung, Present and Future Perspective on Electrode Materials for Rechargeable Zinc-Ion Batteries, Acs Energy Letters, 3 (2018) 2620-2640.

[54] E. Cauet, S. Bogatko, J.H. Weare, J.L. Fulton, G.K. Schenter, E.J. Bylaska, Structure and dynamics of the hydration shells of the $\mathrm{Zn} 2+$ ion from ab initio molecular dynamics and combined ab initio and classical molecular dynamics simulations, Journal of Chemical Physics, 132 (2010).

[55] A. Krezel, W. Maret, The biological inorganic chemistry of zinc ions, Archives of Biochemistry and Biophysics, 611 (2016) 3-19.

[56] B. Beverskog, I. Puigdomenech, Revised Pourbaix diagrams for zinc at 25-300 degrees C, Corrosion Science, 39 (1997) 107-114.

[57] A.R. Mainar, E. Iruin, L.C. Colmenares, A. Kvasha, I. de Meatza, M. Bengoechea, O. Leonet, I. Boyano, Z.C. Zhang, J.A. Blazquez, An overview of progress in electrolytes for secondary zinc-air batteries and other storage systems based on zinc, Journal of Energy Storage, 15 (2018) 304-328.

[58] J.F. Parker, C.N. Chervin, E.S. Nelson, D.R. Rolison, J.W. Long, Wiring zinc in three dimensions re-writes battery performance-dendrite-free cycling, Energy \& Environmental Science, 7 (2014) 1117-1124.

[59] H.F. Li, C.J. Xu, C.P. Han, Y.Y. Chen, C.G. Wei, B.H. Li, F.Y. Kang, Enhancement on Cycle Performance of Zn Anodes by Activated Carbon Modification for Neutral Rechargeable Zinc Ion Batteries, Journal of the Electrochemical Society, 162 (2015) A1439-A1444.

[60] L.P. Wang, N.W. Li, T.S. Wang, Y.X. Yin, Y.G. Guo, C.R. Wang, Conductive graphite fiber as a stable host for zinc metal anodes, Electrochimica Acta, 244 (2017) 172-177.

[61] X.W. Wang, F.X. Wang, L.Y. Wang, M.X. Li, Y.F. Wang, B.W. Chen, Y.S. Zhu, L.J. Fu, L.S. Zha, L.X. Zhang, Y.P. Wu, W. Huang, An Aqueous Rechargeable Zn//Co3O4 Battery with High Energy Density and Good Cycling Behavior, Advanced Materials, 28 (2016) 4904-4911.

[62] L.T. Kang, M.W. Cui, F.Y. Jiang, Y.F. Gao, H.J. Luo, J.J. Liu, W. Liang, C.Y. Zhi, Nanoporous CaCO3 Coatings Enabled Uniform Zn Stripping/Plating for Long-Life Zinc Rechargeable Aqueous Batteries, Advanced Energy Materials, 8 (2018).

[63] K.E.K. Sun, T.K.A. Hoang, T.N.L. Doan, Y.Y.X. Zhu, Y. Tian, P. Chen, Suppression of Dendrite Formation and Corrosion on Zinc Anode of Secondary Aqueous Batteries, Acs Applied Materials \& Interfaces, 9 (2017) 9681-9687.

[64] D.A. Kitchaev, S.T. Dacek, W.H. Sun, G. Ceder, Thermodynamics of Phase Selection in MnO2 Framework Structures through Alkali Intercalation and Hydration, Journal of the American Chemical Society, 139 (2017) 2672-2681.

[65] M. Pourbaix, Atlas of Electrochemical Equilibria in Aqueous Solutions, National Association of Corrosion Engineers1966. 
[66] M.H. Alfaruqi, J. Gim, S. Kim, J. Song, J. Jo, S. Kim, V. Mathew, J. Kim, Enhanced reversible divalent zinc storage in a structurally stable alpha-MnO2 nanorod electrode, Journal of Power Sources, 288 (2015) 320327.

[67] H.L. Pan, Y.Y. Shao, P.F. Yan, Y.W. Cheng, K.S. Han, Z.M. Nie, C.M. Wang, J.H. Yang, X.L. Li, P. Bhattacharya, K.T. Mueller, J. Liu, Reversible aqueous zinc/manganese oxide energy storage from conversion reactions, Nature Energy, 1 (2016).

[68] B. Lee, C.S. Yoon, H.R. Lee, K.Y. Chung, B.W. Cho, S.H. Oh, Electrochemically-induced reversible transition from the tunneled to layered polymorphs of manganese dioxide, Scientific Reports, 4 (2014).

[69] B. Lee, H.R. Lee, H. Kim, K.Y. Chung, B.W. Cho, S.H. Oh, Elucidating the intercalation mechanism of zinc ions into alpha-MnO2 for rechargeable zinc batteries, Chemical Communications, 51 (2015) 9265-9268.

[70] B. Lee, H.R. Seo, H.R. Lee, C.S. Yoon, J.H. Kim, K.Y. Chung, B.W. Cho, S.H. Oh, Critical Role of pH Evolution of Electrolyte in the Reaction Mechanism for Rechargeable Zinc Batteries, Chemsuschem, 9 (2016) 2948-2956.

[71] D. Kundu, B.D. Adams, V.D. Ort, S.H. Vajargah, L.F. Nazar, A high-capacity and long-life aqueous rechargeable zinc battery using a metal oxide intercalation cathode, Nature Energy, 1 (2016).

[72] M.Y. Yan, P. He, Y. Chen, S.Y. Wang, Q.L. Wei, K.N. Zhao, X. Xu, Q.Y. An, Y. Shuang, Y.Y. Shao, K.T. Mueller, L.Q. Mai, J. Liu, J.H. Yang, Water-Lubricated Intercalation in V2O5 center dot nH(2)O for HighCapacity and High-Rate Aqueous Rechargeable Zinc Batteries, Advanced Materials, 30 (2018).

[73] R. Trocoli, F. La Mantia, An Aqueous Zinc-Ion Battery Based on Copper Hexacyanoferrate, Chemsuschem, 8 (2015) 481-485.

[74] F. Wang, Y.X. Lin, L.M. Suo, X.L. Fan, T. Gao, C.Y. Yang, F.D. Han, Y. Qi, K. Xu, C.S. Wang, Stabilizing high voltage LiCoO2 cathode in aqueous electrolyte with interphase-forming additive, Energy \& Environmental Science, 9 (2016) 3666-3673.

[75] L.M. Suo, F.D. Han, X.L. Fan, H.L. Liu, K. Xu, C.S. Wang, "Water-in-Salt" electrolytes enable green and safe Li-ion batteries for large scale electric energy storage applications, Journal of Materials Chemistry A, 4 (2016) 6639-6644.

[76] N. Dubouis, P. Lemaire, B. Mirvaux, E. Salager, M. Deschamps, A. Grimaud, The role of the hydrogen evolution reaction in the solid-electrolyte interphase formation mechanism for "Water-in-Salt" electrolytes, Energy \& Environmental Science, 11 (2018) 3491-3499.

[77] Y. Yamada, K. Usui, K. Sodeyama, S. Ko, Y. Tateyama, A. Yamada, Hydrate-melt electrolytes for highenergy-density aqueous batteries, Nature Energy, 1 (2016).

[78] F. Wang, O. Borodin, T. Gao, X.L. Fan, W. Sun, F.D. Han, A. Faraone, J.A. Dura, K. Xu, C.S. Wang, Highly reversible zinc metal anode for aqueous batteries, Nature Materials, 17 (2018) 543-+.

[79] S. Gheytani, Y.L. Liang, Y. Jing, J.Q. Xu, Y. Yao, Chromate conversion coated aluminium as a lightweight and corrosion-resistant current collector for aqueous lithium-ion batteries, Journal of Materials Chemistry A, 4 (2016) 395-399.

[80] W.J. Clark, R.L. McCreery, Inhibition of corrosion-related reduction processes via chromium monolayer formation, Journal of the Electrochemical Society, 149 (2002) B379-B386.

[81] R.V. Mom, J. Cheng, M.T.M. Koper, M. Sprik, Modeling the Oxygen Evolution Reaction on Metal Oxides: The Infuence of Unrestricted DFT Calculations, Journal of Physical Chemistry C, 118 (2014) 40954102.

[82] J.K. Norskov, T. Bligaard, A. Logadottir, J.R. Kitchin, J.G. Chen, S. Pandelov, J.K. Norskov, Trends in the exchange current for hydrogen evolution, Journal of the Electrochemical Society, 152 (2005) J23-J26.

[83] S.J. Visco, V.Y. Nimon, A. Petrov, K. Pridatko, N. Goncharenko, E. Nimon, L. De Jonghe, Y.M. Volfkovich, D.A. Bograchev, Aqueous and nonaqueous lithium-air batteries enabled by water-stable lithium metal electrodes, Journal of Solid State Electrochemistry, 18 (2014) 1443-1456. 
[84] K. Koshika, N. Chikushi, N. Sano, K. Oyaizu, H. Nishide, A TEMPO-substituted polyacrylamide as a new cathode material: an organic rechargeable device composed of polymer electrodes and aqueous electrolyte, Green Chemistry, 12 (2010) 1573-1575.

[85] K. Hatakeyama-Sato, H. Wakamatsu, R. Katagiri, K. Oyaizu, H. Nishide, An Ultrahigh Output Rechargeable Electrode of a Hydrophilic Radical Polymer/Nanocarbon Hybrid with an Exceptionally Large Current Density beyond $1 \mathrm{~A} \mathrm{~cm}(-2)$, Advanced Materials, 30 (2018).

[86] S. Perticarari, E. Grange, T. Doizy, Y. Pellegrin, E. Quarez, K. Oyaizu, A.J. Fernandez-Ropero, D. Guyomard, P. Poizot, F. Odobel, J. Gaubicher, Full Organic Aqueous Battery Based on TEMPO Small Molecule with Millimeter-Thick Electrodes, Chemistry of Materials, 31 (2019) 1869-1880.

[87] E.J. Berg, C. Villevieille, D. Streich, S. Trabesinger, P. Novak, Rechargeable Batteries: Grasping for the Limits of Chemistry, Journal of the Electrochemical Society, 162 (2015) A2468-A2475.

[88] D. Eroglu, S. Ha, K.G. Gallagher, Fraction of the theoretical specific energy achieved on pack level for hypothetical battery chemistries, Journal of Power Sources, 267 (2014) 14-19. 